\title{
NEURO-STRUCTURAL ANALYSIS OF THE FAST, SEIZURE- PRONE RAT STRAIN VS. THE SLOW, SEIZURE-RESISTANT RAT STRAIN USING MAGNETIC RESONANCE IMAGING (MRI) AND STEREOLOGY
}

by

Michael A. D. Vandenberg

A thesis submitted to the Faculty of Graduate and Postdoctoral Affairs in partial fulfillment of the requirements for the degree of

Master of Science

in

Neuroscience

Carleton University

Ottawa, Ontario

(C) 2011

Michael A. D. Vandenberg 
Library and Archives
Canada

Published Heritage

Branch

395 Wellington Street

Ottawa ON K1A ON4

Canada
Bibliothèque et

Archives Canada

Direction du

Patrimoine de l'édition

395, rue Wellington

Ottawa ON K1A 0N4

Canada
Your file Votre référence

ISBN: 978-0-494-81682-0

Ourfile Notre référence

ISBN: 978-0-494-81682-0
NOTICE:

The author has granted a nonexclusive license allowing Library and Archives Canada to reproduce, publish, archive, preserve, conserve, communicate to the public by telecommunication or on the Internet, loan, distribute and sell theses worldwide, for commercial or noncommercial purposes, in microform, paper, electronic and/or any other formats.

The author retains copyright ownership and moral rights in this thesis. Neither the thesis nor substantial extracts from it may be printed or otherwise reproduced without the author's permission.
AVIS:

L'auteur a accordé une licence non exclusive permettant à la Bibliothèque et Archives Canada de reproduire, publier, archiver, sauvegarder, conserver, transmettre au public par télécommunication ou par l'Internet, prêter, distribuer et vendre des thèses partout dans le monde, à des fins commerciales ou autres, sur support microforme, papier, électronique et/ou autres formats.

L'auteur conserve la propriété du droit d'auteur et des droits moraux qui protège cette thèse. $\mathrm{Ni}$ la thèse ni des extraits substantiels de celle-ci ne doivent être imprimés ou autrement reproduits sans son autorisation.
In compliance with the Canadian Privacy Act some supporting forms may have been removed from this thesis.

While these forms may be included in the document page count, their removal does not represent any loss of content from the thesis.
Conformément à la loi canadienne sur la protection de la vie privée, quelques formulaires secondaires ont été enlevés de cette thèse.

Bien que ces formulaires aient inclus dans la pagination, il n'y aura aucun contenu manquant. 


\begin{abstract}
The FAST rat strain has long been accepted as animal models of susceptibility for the development of epilepsy, but recently it has been suggested that the strain also exhibits some of the more common behavioural characteristics found in the autistic spectrum of disorders (ASD). It was the goal of this study to examine, at a structural and molecular level how the FAST and SLOW strains differ. The frontal lobes, corpus callosum and cerebellum were chosen for their involvement in both epilepsy and ASD pathology. Results include that the FAST strain displays a significantly higher volume in the corpus callosum and anterior cerebellum compared to SLOWs, while they showed smaller volumes in the posterior cerebellum. Stereology of the cerebellum revealed that the FAST strain possess fewer Purkinje cells than their SLOW counterparts but the white matter layer of the cerebellum is larger than in the seizure-resistant strain. These results offer a mixed bag when compared to the human disorders of interest; while MRI and stereology data from the cerebellum matches up very well with both ASD and epilepsy literature, an increase in corpus callosum volume flies directly in the face of the accepted data.
\end{abstract}




\section{Acknowledgements}

I would like to extend my deepest thanks to my family and friends for their endless support throughout the ordeal that is a Master's thesis. Mom, Dad, Kristen; I never would have finished this thing without your constant encouragement, I don't know how I'll ever repay you.

I would like to offer my endless gratitude to Dr. Dan McIntyre for supervising my project in a field for which I have a special connection. A thanks to Dr. Krista Gilby for her support and guidance, without which my project would have had no direction. Thank you to Dr. Alfonso Abizaid and Dr. John Stead for their guidance and support through the writing process, and thanks to every student I've had the pleasure of working with in the lab over the years. Without that sense of community it would have been that much harder to get this done.

Finally, Sarah, you kept me sane through this whole endeavour. I know I've been difficult to deal with these past years but you've stuck with me through it all, I am eternally grateful for your support. 


\section{Table of Contents}

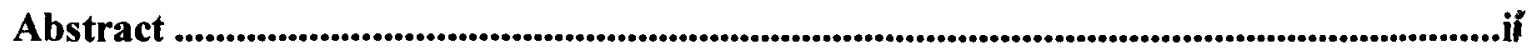

Acknowledgements ....................................................................................................... iii

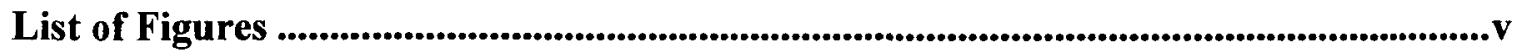

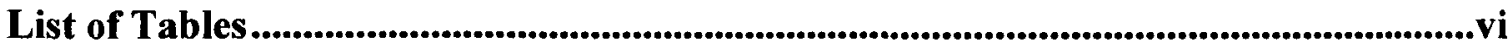

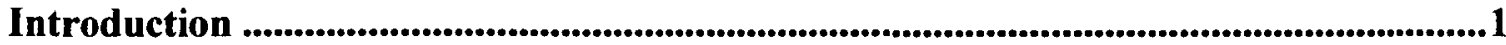

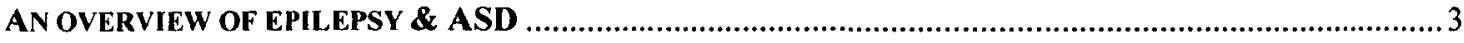

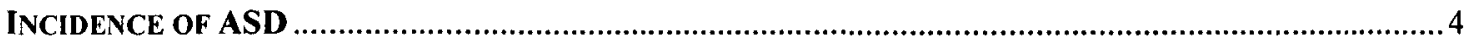

FAST AND SLOW STRAINS: SUSCEPTIBILITY TO TEMPORAL LOBE EPILEPSY ...............................5

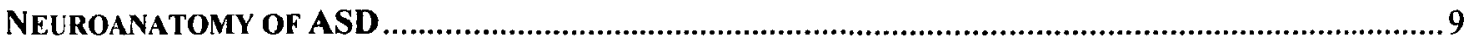

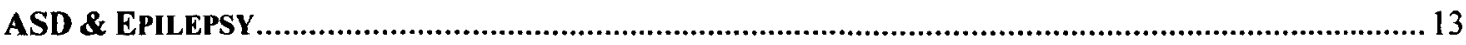

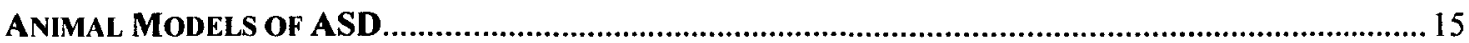

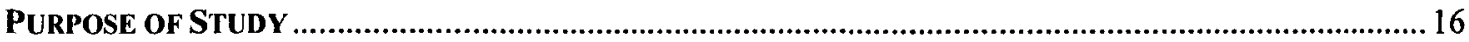

Materials and Methods....................................................................................................18

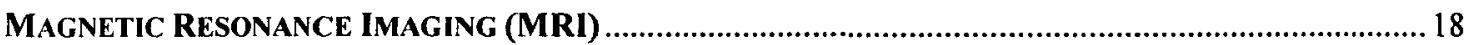

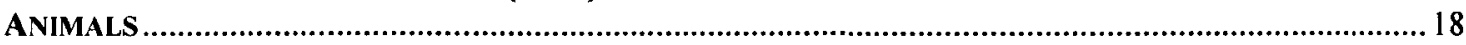

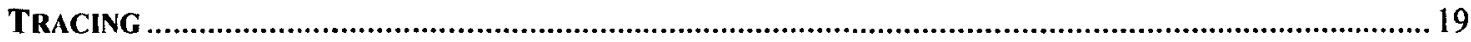

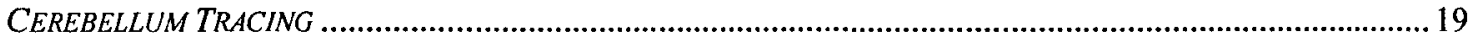

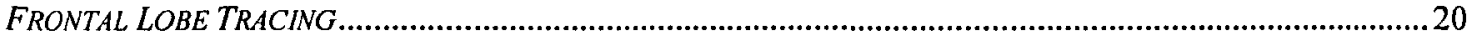

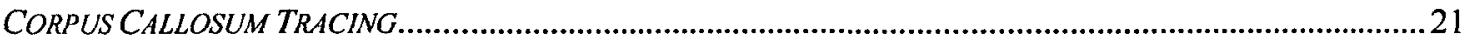

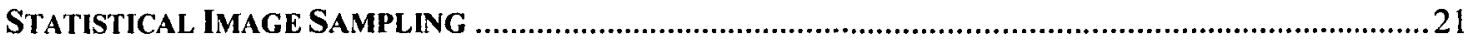

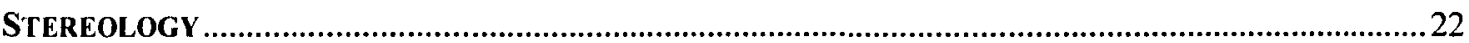

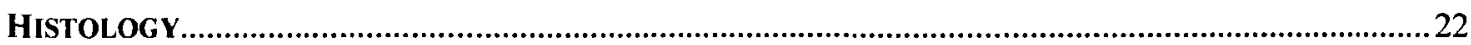

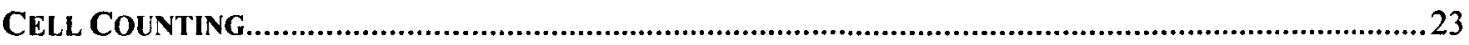

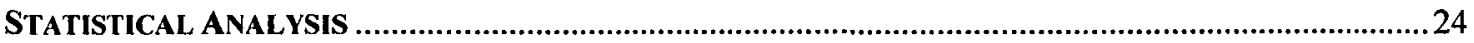

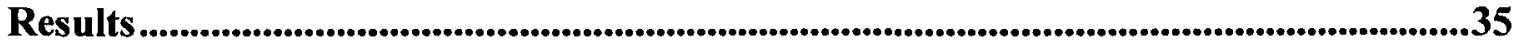

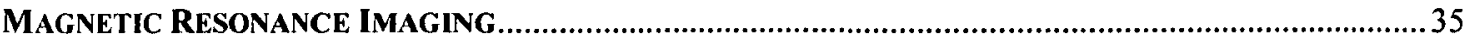

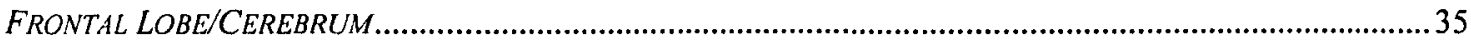

CORPUS CALLOSUM

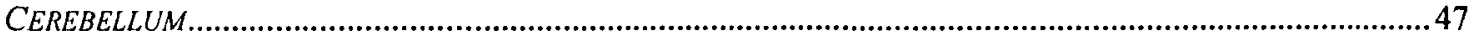

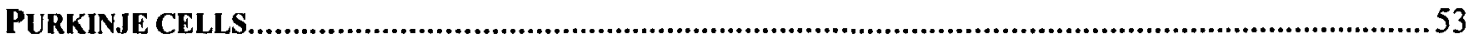

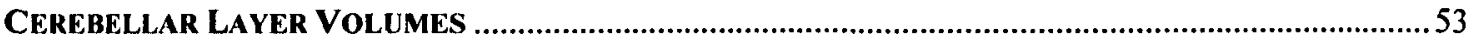

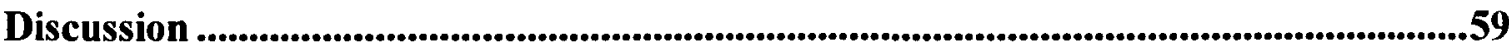

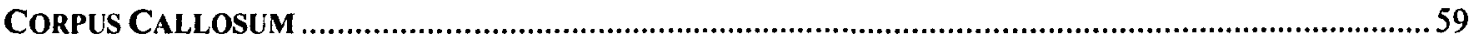

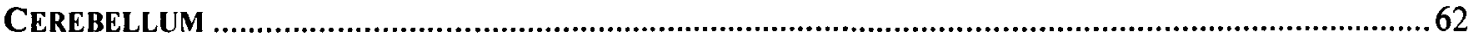

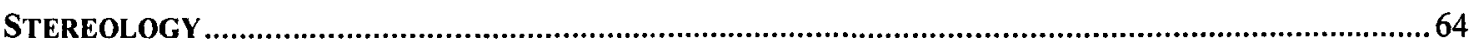

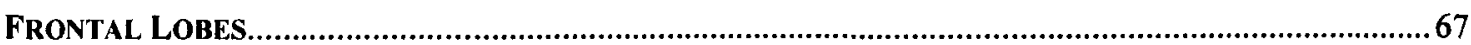

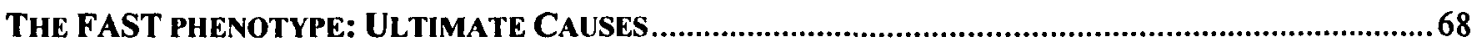

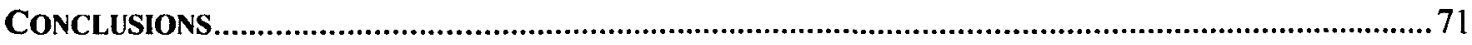

References.......................................................................................................................73 


\section{List of Figures}

Figure 1: MRI images of cerebellar lobules 8-10 (A) and lobues 6-7 (B)......................25

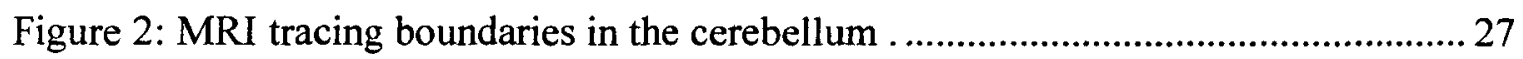

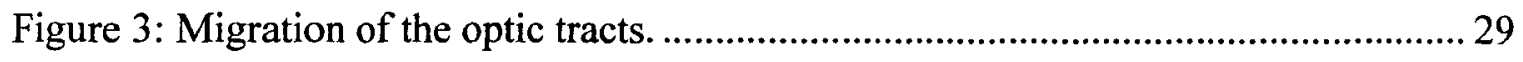

Figure 4: Counting frame used to estimate Purkinje cell population................................. 31

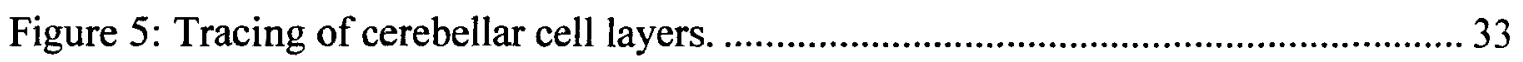

Figure 6: Between-strain comparison of frontal lobe volume ......................................... 38

Figure 7: Three dimensional reconstruction of the cerebral hemispheres in FAST and

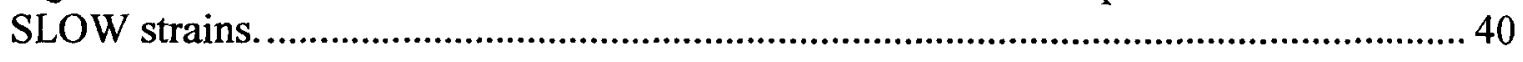

Figure 8: Corpus callosum volume in FAST vs. SLOW strains...................................... 43

Figure 9: Three dimensional reconstruction of the corpus callosum in FAST and SLOW

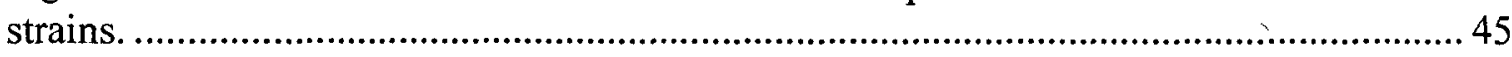

Figure 10: Between-strain comparison of cerebellar sub-region volume.......................... 49

Figure 11: Purkinje cell counts in FAST vs. SLOW strains ............................................. 54

Figure 12: Between strains comparison of cell layer volumes. .......................................57 


\section{List of Tables}

Table 1: Frontal lobe tracing of FAST and SLOW............Error! Bookmark not defined.

Table 2: Volume of the corpus callosum in FAST and SLOW rats. Error! Bookmark not defined.

Table 3: MRI traced volume of cerebellar sub-regions. ....Error! Bookmark not defined.

Table 4: Correlations between structure volumes in the FAST rat strain...................Error! Bookmark not defined.

Table 5: Correlations between structure volumes in the SLOW rat strain. Error! Bookmark not defined.

Table 6: Tissue volume of cerebellar cell layers in the FAST and SLOW rat strainsError! Bookmark not defined.

Table 7: Results summary 65 


\section{Introduction}

In the study of human disease, animal models can be developed in a number of ways and are extremely useful to researchers, because they serve as a cheaper, simpler and more efficient alternative to study most conditions than using human subjects. It is sometimes possible to find a 'human' disease occurring naturally in other species allowing researchers to conduct much more detailed experimentation than would be possible on human subjects. More recently, thanks to advancements in genetic analysis and molecular biology, animal models of disease have been developed by using information about the etiology of a human disease to modify or select for the required characteristics, genetic or otherwise, in simpler species, and thereby recreate the desired condition.

Unfortunately, our understanding of disease genetics remains in its infancy, and we have not yet identified precise mechanistic underpinnings to many disorders. In the case of autism spectrum disorders (ASDs), it has been well established that there is a strong heritable component to ASD. Children from families with at least one affected family member are 25-100 times more likely to develop ASD than those whose families are unaffected (Bolton et al., 1994). Despite this strong correlation, no simple genetic cause has been isolated that can account for a significant percentage of reported ASD cases. In fact, dozens of individual genes have been found (eg. NLGN4, NRXN1, SHANK3) (Abrahams \& Geschwind, 2010) that can be linked to over 15\% of ASD cases, but no individual gene has been conclusively linked to more than $1 \%$ of cases (Geschwind, 2008). Rather than contributing to the understanding of autism, these genetic disorders are often spun off into their own category. An example of this is fragile $X$ syndrome, which once accounted for $\sim 2 \%$ of reported autism cases before its root 
cause was identified, but now are not reported in the same statistical category (Wassink, Piven, \& Patil, 2001).

This genetic and symptomatic heterogeneity creates a serious problem for researchers who have in the past developed treatments for diseases that had a more simple and homogeneous cause.

Adding to the difficulty in studying the autistic spectrum of disorders is that diagnosis is limited to behaviourally defined criteria. Thus, in order to study this condition, researchers have relied heavily on developing their own strains of animals that display a good number of the behavioural or biological traits (Klauck \& Poustka, 2006; Bourgeron, Jamain, \& Granon, 2006) associated with ASDs, but now face the daunting task of experimentally showing that their models are appropriate as more deterministic biomarkers emerge on anatomical, physiological and neurochemical levels.

The goal of this thesis is to compare the FAST strain of rats, originally developed by Racine et al. for heightened seizure sensitivity in the kindling model (Racine, Steingart, \& McIntyre, 1999), and their SLOW strain cousins, developed for resistance to the development of epilepsy, on a structural level using MRI \& stereology. Differences in structure size or organization could offer a new perspective on the underlying developmental origins of the phenotypes seen in the two strains. In the course of this study, the differences seen between strains will also be compared to the established literature with respect to both autistic and epileptic brains. The FAST strain has shown a number of behavioural similarities to an autistic phenotype, but no research has yet been done to determine whether the brain morphology itself shows any significant similarities. 


\section{An overview of epilepsy \& ASD}

Epilepsy, a condition in which an individual suffers from repeated seizures, is a very complicated disorder that, while widespread and relatively common (Banerjee, Filippi, \& Hauser, 2009), has a cause that varies almost person to person. The International League against Epilepsy recognizes over 40 distinct types of epilepsy, each with a distinct cause (trauma, neurodegeneration, environmental exposure, etc.), and often having radically different points of focus in the brain (Engel, 2006). The FAST \& SLOW strains were developed for susceptibility and resistance of developing seizures originating in the amygdala and surrounding structures, classified broadly as temporal lobe epilepsy (TLE).

ASD is an umbrella term applied to a collection of childhood developmental disorders involving marked delays in social interaction, communication and motor development. It is classified by the DSM-IV into three subtype categories: autistic disorder, Asperger's disorder \& pervasive developmental disorder - not otherwise specified (PDD-NOS), also known as atypical autism. ASD is one of the most common disorders affecting children worldwide, with recent estimates pointing to an annual incidence of approximately 1 in 170 children (Fombonne, 2003). A positive diagnosis of ASD is typically made when a child meets a number of behavioural criteria, which are divided into three categories: (1) qualitative impairment in social interaction, (2) qualitative impairments in communication and (3) restricted repetitive and stereotyped patterns of behaviour, interests and activities (American Psychological Association, 2000). In addition to these requirements, a child must also show a delayed or abnormal functioning before the age of three in at least one of: social interaction, social communication, symbolic or imaginative play. 


\section{Incidence of ASD}

In recent years, ASD has become one of the most heavily publicized and researched childhood developmental disorders, due in part to a perceived increase in prevalence in the general public. Early studies from the 1980 s and 90 s found that the incidence (number of new cases in a given year) of ASD was approximately $27.5 / 10,000$ (Rutter, 2005), while studies from the past decade have measured an incidence nearly three times higher, between 60-70/10,000 (Fombonne, 2002; Hertz-Picciotto, 2008). This measured change in the incidence of ASD has led some to believe that there is an epidemic of ASD sweeping the developed world, but there is still a great deal of debate as to the legitimacy of the reported numbers (Gernsbacher, Dawson, \& Goldsmith, 2005; Leonard et al., 2010).

The most recent estimate of ASD prevalence (all living cases) found that approximately $2 \%$ of children in North America and Europe are currently affected by a disorder that can be classified under the ASD umbrella (Polanczyk, de Lima, Horta, Biederman, \& Rohde, 2007; Kogan et al., 2008). As outlined by Dr. Eric Fombonne (2003), a likely cause of the perceived rise in the incidence could be due to the methods by which ASD is diagnosed by clinicians and researchers steadily changing and evolving over time, starting in the mid 20th century. Early epidemiological studies in the $60 \mathrm{~s}$ and 70s failed to include Asperger's syndrome (AS) or pervasive developmental disorder (atypical autism) in their statistics, which now account for more than half of ASD diagnoses in North America (Fombonne, 2002; Shattuck, 2006), likely resulting in significant under diagnosis and reporting in these decades. Because of the ever changing methodology, including both better detection methods and a broadening of the clinical 
definition of ASD, it is nearly impossible to say whether or not the rates of incidence are in fact increasing over time. Another side-effect of inconsistent diagnostic criteria is that each country and/or culture has developed its own standards as to what constitutes an ASD case.

It should also be discussed that there are a number of environmental factors that have been implicated in the rise in incidence, most comprehensively reviewed in (Deth, Muratore, Benzecry, Power-Charnitsky, \& Waly, 2008). In his paper, Deth argues that a combination of genetic susceptibility and environmental exposure to heavy metals and xenobiotics may cause a great deal of oxidative stress leading to altered patterns of methylation in human DNA. These changes in methylation patterns can not only alter gene function in the affected individual but can be passed down epigenetically to subsequent generations. These environmental factors may help to explain regional differences in reported ASD rates.

Because of this it is incredibly difficult to combine statistics from separate regions or assess the reach of ASD on a global scale. One can only hope that medical science will reach a point in the near future where rates of diagnosis stabilize and the true prevalence of the disorder reveals itself, and thus confirms whether or not ASD is indeed in a state of epidemic increase.

\section{FAST and SLOW Strains: Susceptibility to temporal lobe epilepsy}

The seizure prone (FAST) and seizure resistant (SLOW) rat strains were initially bred to determine whether or not susceptibility towards seizures could be explained genetically. From a parent population of Wistar rats crossed with Long Evans Hooded rats, they were selectively bred based on the number of stimulations (kindling rate) 
required to reach a stage 5 convulsive seizure in the kindling paradigm using direct amygdala stimulation (Racine et al., 1999). Rats exhibiting relatively faster kindling rates were bred together and their offspring (following several generations) established the seizure-prone, FAST strain. At the other end of the spectrum, relatively slow to kindle rats were bred together over successive generations to create the seizure-resistant, SLOW strain.

Interestingly, despite a selective breeding criterion based in seizure sensitivity alone, FAST rats have evolved to naturally exhibit a number of ADHD/ASD-like behaviours that are significantly different from both SLOW rats and their parental strains. Experiments have shown that in the context of a restraint paradigm, FAST rats struggle much longer than their SLOW counterparts, who more closely behave like their parental strains in that testing paradigm (McIntyre, Kent, Hayley, Merali, \& Anisman, 1999; Gilby, Thorne, Patey, \& McIntyre, 2007). This behaviour could represent a measure of hyperactivity and anxiety, two of the hallmark behavioural traits seen in human cases of ASD. Perhaps an even better example of this behaviour lies in the FAST strain's sexual impulsivity. Males from both the SLOW strain and parental strains react as would be expected when in the presence of a female: if in estrous and receptive, they will approach and attempt to mount, but otherwise keep their distance. The FAST animals on the other hand will attempt to mount any female in their presence, regardless of estrous state or receptiveness. This often leads to violent confrontations, but does not alter their approach behaviour (McIntyre, Poulter, \& Gilby, 2002).

FAST rats also exhibit, in a Morris water maze, a great deal of difficulty focusing on their learning task when simple distracting cues are introduced into the environment. Their time to complete the task is significantly higher when compared to SLOW rats 
(Anisman \& McIntyre, 2002), due in large part to their inability to hold attention on the task. In open field experiments (McIntyre et al., 2002), FAST rats do not show 'normal' habituation to a novel environment, while SLOW rats show the expected reduction in locomotor activity across consecutive trials as they became more comfortable in the novel environment. It has also been noted that FAST rats occasionally ( $1 \%$ of individuals) exhibit stereotyped behaviour such as compulsive grooming of both themselves and their offspring, compulsive scratching behaviours to the point of skin lesion, a tendency to repetitively circle their cages and, finally, to repetitively move their pups from one nesting location to another (Gilby, 2008).

A study in 2004 (Reinhart, Pellis, \& McIntyre, 2004) compared the two strains in their style of play-fighting with peers of the same strain and age, both as juveniles and as adults. The study found that FAST rats were more active in play-fighting both as juveniles and adults, being aggressive and defensive significantly more often than their SLOW counterparts. Strain defence strategies also differed significantly, with the SLOW strain maintaining approximately the same levels of evasive and confrontational strategies, while FAST subjects became much more evasive in adulthood, choosing to move away from a fight rather than face their attacker head-on. These findings serve as an excellent example of the higher impulsivity and nervousness typical of the FAST phenotype. This high-energy anxiety and hyperactivity should not be confused with low level, chronic anxiety which has been shown to be more prominent in the SLOW strain.

Perhaps the most powerful ASD-like trait expressed by the FAST rats is a profound neurodevelopmental delay. FAST rats show a significant delay/deficit in several developmental milestones, including post-natal eye opening, cliff avoidance and righting reflex when compared to their SLOW counterparts (St. Onge, MSc. Thesis, 
2009). It is also worth noting that within the past two decades, a decline in dietary intake of essential fatty acids (EFAs) has paralleled the perceived increase in ASD diagnoses (Richardson \& Puri, 2002), and that ASD children and adults exhibit significantly lowered plasma concentrations of EFAs (particularly omega-3s and omega-6s) (Colter, Cutler, \& Meckling, 2008; Young, Maharaj, \& Conquer, 2004; Young \& Conquer, 2005). It has also been reported that patients suffering from epilepsy show a similar pattern of EFA deficiency and that supplementation is capable of controlling seizures in a significant number of cases (Yuen et al., 2005; Rabinovitz, Mostofsky, \& Yehuda, 2004; Schlanger, Shinitzky, \& Yam, 2002). The FAST strain, similarly, shows much lower free fatty acid (FFA) concentrations than their SLOW counterparts (Gilby, Jans, \& McIntyre, 2009). More specifically, in-depth FFA analysis (Gilby, K., unpublished raw data, 2009) has shown that there are a number of FFAs that are over- and underrepresented in the blood of FAST rats, the clearest example of which are the $n 7$ class of fatty acids $(16: 1 \mathrm{n} 7$ and 18:1n7). These FFAs are severely underrepresented in the FAST strain compared to the SLOW strain, and it is hypothesized that this is likely due to dysfunction of the protein $\Delta 9$ desaturase, which synthesizes $n 7$ FFAs from saturated fats. Where this relates back to the developmental delay is that myelin, which forms the protective sheath around a mature axon, is approximately $80 \%$ fat (Obrien \& Sampson, 1965). This means that myelin development could be significantly altered if lipid handling is impaired in any way. Recent data from Western Blot has shown conclusively (Gilby, K., unpublished raw data, 2010) that the FAST animals are deficient in two key proteins: myelin-basic protein (MBP), which is responsible for myelin sheath organization and maintenance, and proteolipid protein (PLP), the most common and abundant myelin protein (Edwards, Ross, Ulmer, \& Braun, 1989; Klugmann et al., 1997). 
Dietary supplementation with omega-3 fatty acids did not significantly alter the FAST strain's kindling rate, after-discharge threshold or after-discharge duration, but did increase the SLOW strain's susceptibility to kindling, reducing significantly the number of stimulations required to reach a stage 5 seizure. Behaviourally, dietary intervention had no effect on either strain, except for the FAST strain in a restraint task, where their attempts to escape restraint, usually significantly more than SLOWs, was brought directly in line with the other strain.

Taken together, these behavioural and physiological differences seen in the FAST versus SLOW strain seem very similar to the hyperactivity, lack of focus and social difficulties seen in human ASD patients. While more experiments are needed to strengthen these observed parallels with the human condition, there is certainly enough evidence already to warrant a more in-depth look at the neuroanatomical differences that may exist between the strains, and how they may compare with experimental data gathered from human studies. These clinical and laboratory findings underscore one of the major comorbid features between ASD and epilepsy, and the finding that FAST rats behave much in the same way as human ASD patients is strong evidence for research into the validity of the strain as an animal model of ASD.

\section{Neuroanatomy of ASD \& Epilepsy}

One of the newest tools available to researchers for the study of the brain is magnetic resonance imaging (MRI), which has in the past 20 years given scientists the ability to intricately examine the human brain in vivo, observing the anatomy of a disorder without the need for invasive surgery or post-mortem investigation. Since its introduction there have been dozens of studies published examining which regions of the 
brain are altered in patients with ASD. From these studies has emerged an ever-growing list of structures that could potentially be involved in the pathology of the autistic brain, including the amygdala, thalamus, substantia nigra, anterior cingulate cortex, orbitofrontal cortex, inferior frontal gyrus, cerebellum, corpus callosum and hippocampus (Amaral, Schumann, \& Nordahl, 2008). Despite the wealth of data generated, it is rare to find two studies that present comparable lists. This discrepancy likely reflects both the non-conformity in diagnosis of ASDs and the fact that studies involving human subjects, especially those in which the patients are children, usually involve a small number of participants $(n<15)$ and the power of their findings often reflect the subject limitation (Stanfield et al., 2008).

More recently, there has been an effort to perform meta-analysis on these smaller studies (Bauman \& Kemper, 2005; DiCicco-Bloom et al., 2006; Amaral et al., 2008; Stanfield et al., 2008; Verhoeven, De, Lagae, \& Sunaert, 2010), statistically analyzing the resultant data in an attempt to distil any overarching effects that might help clear up the inconsistencies in the literature. Among the major findings of these meta-analyses include the observation that children diagnosed with ASD have a total brain volume that is $5-10 \%$ larger than those of age-matched, healthy children, usually localized in the frontal lobes, but that this difference is greatest earlier in childhood ( $<5$ years) and often disappears by the onset of puberty (Amaral et al., 2008; Freitag et al., 2010). It is hypothesized that this enlarged brain early in development is due to accelerated brain development and abnormal neuronal migration in the cerebral cortex, which later in childhood (ages 5-10) abates to a growth rate slower than what is observed in healthy individuals, at which time a normally developing brain has the opportunity to 'catch up' to the volume of an ASDaffected brain (Hazlett et al., 2005). It is important to note however that there is still 
strong debate as to whether the difference in brain volume is due to primarily grey or white matter; there have been studies published in favour of both cases (Ke et al., 2009; Ecker et al., 2010). Further adding to the confusion, a recent paper published by Freital et al. (2009) found that both grey matter and white matter were equally affected in the cortex, contributing equally to a larger total cortex volume.

Abnormalities in the cerebellum of ASD patients have also held strong in the meta analysis, specifically a smaller volume of lobules 6-7(Stanfield et al., 2008), and that this difference in volume was directly correlated with patients' IQ score. Despite this volume reduction within a specific region, the overall volume of the cerebellum in ASD patients is consistently observed to be greater than controls by approximately $10 \%$ across all age groups. Interestingly, Carper \& Courchesne (2000) also found, using MRI, an inverse correlation between the volume of the frontal cortex of young children (mean age 5.4 years) and the volume of cerebellar lobules 6-7, which as previously established were significantly reduced.

Another structure consistently shown in literature to be altered in ASD patients relative to healthy controls is the corpus callosum, with several studies reporting a significantly reduced total volume when compared to total cortex volume (Freitag et al., 2010; Boger-Megiddo et al., 2006; Vidal et al., 2006). This difference in volume has been traced back, using voxel-based morphometry, to a reduced number of axonal connections primarily in the posterior regions of the corpus callosum. These fibers normally innervate the somatosensory cortex as well as regions of the temporal lobe, so reduced connectivity between the hemispheres could have some very serious consequences with respect to sensory recognition and organization. They are also heavily involved in the development of temporal lobe epilepsy (TLE), and damaged fibers could represent an easy way by 
which other brain structures can be quickly recruited into a developing seizure due to a reduced threshold of excitability (McIntyre \& Gilby, 2008).

Other structures that have received significant attention and have been reported to be altered in ASD patients include the amygdala and hippocampus, both of which are integrally important in TLE development, and are both found to be enlarged relative to controls, though amygdala volumes do not seem to differ in post-pubescent subjects (Schumann et al., 2004). The hippocampus, on the other hand, has been the structure around which most contentious arguments have been formed in TLE research. For decades there has been intense debate about whether hippocampal sclerosis, a loss of pyramidal and granule cells, was the cause of or caused by the development of TLE (Jeffreys, 1999). While there is still some argument, the advent of MRI has allowed researchers to monitor the development of the sclerosis in live patients and questions surrounding its nature may be soon forthcoming. Because of these more serious inconsistencies, it is difficult to discuss with any authority the potential role any anatomical differences play in the symptomology observed in ASD patients.

A clear understanding of the anatomy associated with TLE, ASD and any significant overlap would greatly accelerate the rate of research into the underlying mechanisms responsible for both conditions. With a more clearly defined roadmap, it is likely that more precise diagnoses could be made and more specific and effective treatments could be developed. While the rat brain is not $100 \%$ analogous to the human brain, the gross morphology and connective circuitry between regions relevant to this study are similar enough for strong comparisons to be made. 


\section{ASD \& Epilepsy}

One of the most studied comorbid conditions with ASDs is epilepsy, due to their high co-occurrence rate. It has been reported that in children with ASDs, the prevalence of epilepsy rises from $2-5 \%$, the typically reported prevalence in a healthy population, to somewhere between $8-40 \%$, depending on the geographical location of a particular study (Danielsson, Gillberg, Billstedt, Gillberg, \& Olsson, 2005; Tuchman \& Rapin, 2002) and further studies have shown that even those ASD patients that do not show overt seizures may have minor neurological impairments that make them more sensitive to developing seizures under certain circumstances. In addition to this, there is an extremely low rate of remission in patients with both ASD and epilepsy at only 16\% lifetime (Levisohn, 2007; Canitano, 2007), compared to $68-73 \%$ in the healthy population (Cockerell, Sander, \& Shorvon, 1995; Hara, 2007). The increased prevalence and low remission rates seem to indicate a strong link between these two conditions, and the underlying mechanisms that lead to their respective pathologies might well be intricately related. An understanding of these mechanisms may in time lead to the discovery of a common predisposing mechanism. For this reason, a model of ASD that incorporates a higher than normal susceptibility toward seizure may prove more effective than models based in a more tenuous behavioural similarity.

There has, as of yet, been very little experimental data attempting to link epilepsy and ASD in an animal model, primarily because a universally accepted animal model of ASD does not exist. It is more common, such as in a study conducted in 2008 by Dr. Joao Marin (Marin et al., 2008) to take an established animal model of epilepsy and determine which, if any, behavioural similarities exist between the model strain and what would be expected behaviourally of an individual suffering from ASD. In the 2008 study, it was 
observed that rats with temporal lobe epilepsy induced by pilocarpine injections showed impaired social interactions equivalent to those well documented in human children with ASD.

Another much more recent model that has emerged is the EL mouse, a strain that was originally developed in the 1950s (King \& Lamotte, 1989) and was found to be a good model of idiopathic, generalized epilepsy. Recently (Meidenbauer, Mantis, \& Seyfried, 2011), the EL strain has been shown to display many of the same behavioural characteristics associated with both human ASD and the FAST strain. They have been shown to exhibit deficits in exploratory behaviour, higher incidences of stereotyped activities and exploratory behaviour. Interestingly the researchers found that higher rates of epileptic activity translated into more significant behavioural deviations.

Due to the extreme diversity in proposed clinical causes for the development of epilepsy in any given patient, and more importantly the neuroanatomical changes induced by seizures in these patients depending on the severity of the seizure, there can be extensive neurological trauma. It is extremely difficult to draw any significant parallels anatomically between epilepsy and ASD. The best we can do is examine each structure that has been linked to the development of ASD and explore what data exist, if any, showing anatomical similarities between TLE and ASD. For example, a major clinical feature reported in epilepsy patients is significant atrophy of the cerebellum. It has been shown that in patients diagnosed with chronic epilepsy, the level of cerebellar damage is positively correlated with both the duration of each individual seizure a patient experiences and also the number of seizures a patient is likely to experience in his or her lifetime (Hagemann et al., 2002). When we then examine the literature surrounding ASD, 
we find that there is a similar correlation, whereby greater cerebellar damage is linked to more severe behavioural and cognitive impairments (Webb et al., 2009).

Additionally, there has been significant evidence presented that the corpus callosum differs in patients with TLE, particularly in the more posterior regions (Weber et al., 2007). As mentioned earlier, this has also been reported in patients suffering from ASD, (Boger-Megiddo et al., 2006). One major caveat, however, is that there is no way to determine whether or not damage to the corpus callosum is contributing to TLE susceptibility initially, rather than being damaged by the seizures themselves. More recent studies (Kim, Piao, Liu, Bingaman, \& Diehl, 2008) have shown, by using 'new onset' patients for which there is pre-existing neurological data, that corpus callosum damage is likely caused by seizures and less likely to be involved in their onset.

\section{Animal Models of ASD}

In the past decade there has been a concerted effort by the scientific community to develop an animal model of autism per se and ASDs more generally that applies to as many facets of the condition as possible. Researchers have approached the problem from many angles, including genetic manipulation, lesion modelling, and even in vitro models that examine single-cellular interactions in affected tissues. Unfortunately, in each of these cases, the developed model has only isolated a single genetic factor or observable behaviour, be it a point mutation on the serotonin transporter gene (Gaspar, Cases, \& Maroteaux, 2003) or a cerebellar lesion that produces a more antisocial mouse (Lancaster, Dietz, Moran, \& Pletnikov, 2007). This cannot be considered sufficient for the long term study of ASDs. 
While these models have proven somewhat useful in studying individual symptoms, the heterogeneous nature of ASDs makes developing a behavioural model of the entire condition from the ground up a seemingly impossible task. It is for this reason that some researchers are now taking the approach of 'behaviour first'. Rather than trying to generate the behaviours artificially, scientists look for animals that display a wide range of behaviours associated with autism and then begin to work out the pathology and genetics from there (Belzung, Leman, Vourc'h, \& Andres, 2005). While this process is likely to yield more false-positives, animals that display the behaviour but share none of the anatomical or biological markers of ASDs, it is likely to be a quicker and more costefficient method of finding an appropriate model. In order for a putative animal model of ASD to have any validity, it must be as true as possible to the symptomology, biochemistry and most importantly etiology of this condition in humans.

(Sagvolden, Russell, Aase, Johansen, \& Farshbaf, 2005) provide a review of the validation criteria that would be necessary for a rodent model of ASD, generalized under three sub-categories: face validity, construct validity and predictive validity. In testing face validity, an animal model would ideally show all of the characteristic behavioural abnormalities seen in human patients such as motor impulsiveness, hyperactivity and an inability to sustain attention. By contrast, construct validity requires that a model be similar on a structural level, displaying the same neuropathology, response to pharmaceutical intervention and ultimately the same genetic causes. Once these two criteria have been validated, then hopefully the model will be able to generate predictions as to how human patients might react to various treatments or therapeutic strategies, thus fulfilling the third validation criterion.

\section{Purpose of Study}


The purpose of this study is to use data derived from MRI brain scans of the FAST and SLOW strains to build 3-dimensional images capable of identifying and detailing the anatomical differences between them. More specifically, we used detailed rendering of the MRI scans performed on 23 adult male brains (14 FAST, 9 SLOW) to investigate many of the brain structures that have been determined to be critical to the development of ASD as well as TLE. These include the frontal lobes, corpus callosum and cerebellum, with the cerebellar lobules being divided into three groups: anterior lobules (1-5), posterior lobules (6-7) and flocculonodular lobules (8-10), a common division seen in similar studies (Carper \& Courchesne, 2000; Stanfield et al., 2008). These data were combined with a stereological comparison of Purkinje cell populations and cell layer volume in the cerebellum between 8 individuals from each strain. Ultimately, the data generated by these experiments will hopefully shed some light on the anatomical differences between the strains and how those findings compare to the known neuropathology in both epilepsy and the autistic spectrum of disorders. 


\section{Materials and Methods}

\section{Magnetic Resonance Imaging (MRI)}

\section{Animals}

A total of 23 adult male rats were used in the procurement of post-mortem MRI scans, 14 from the FAST strain and 9 from the SLOW strain. All subjects were approximately 3.5 months of age when they were sacrificed. Rats were kept on a 12 hour light/dark cycle and were given food and water ad libitum. Animals were sacrificed via intracardial perfusion using sodium pentobarbital as a deep anaesthetic, $100 \mathrm{ml} 0.9 \%$ saline, and $100 \mathrm{ml}$ of a $4 \%$ paraformaldehyde solution as the fixative. Following perfusion, the animals were decapitated and brains were stored for shipping in glass vials of $4 \%$ paraformaldehyde solution.

The 23 brains to be scanned were shipped to the Howard Florey Institute, a division of the Royal Melbourne Hospital (RMH) in Melbourne, Australia. The Magnetic Resonance Images (MRI) were acquired from 23 brains on a $4.7 \mathrm{~T}$ (magnetic field strength) Bruker Biospec 47/30 Avance small animal spectrometer (Ettlingen, Germany) using a shielded gradient set (Bruker Biospec) at the Florey Neurosciences Institute, Parkville, Australia. Structural images were obtained contiguously through the entire brain, using a fast spin-echo sequence with a voxel resolution of $0.23 \mathrm{~mm} \times 0.23 \mathrm{~mm} \times$ $0.45 \mathrm{~mm}$, and a field of view $60 \mathrm{~mm} \times 60 \mathrm{~mm}$. The resolution of each image was $256 \times 256$ pixels. RF pulse transmission and MR data acquisition was performed using a $116 \mathrm{~mm}$ inner diameter birdcage coil (Bruker Biospec) optimally tuned. The result of this was 230 images in each orthogonal plane for every brain that was scanned, which were then compiled into single data files that could be read and analyzed by the Analyze software. 


\section{Tracing}

All image processing, tracing and initial statistical analysis was performed with the Analyze 8.1 software package by Analyze Direct. Each set of images was loaded individually into the "Region of Interest" workspace, which by default loaded the most anterior image. From this, each structure was traced by hand using the computer mouse. When tracing was complete in one plane (coronal plane first), the plane was switched and the structure was adjusted so that it lined up properly in all three planes. To better perceive anatomical boundaries, the image could be resized to focus on specific regions and both the brightness and contrast of the image could be adjusted for maximum clarity. Anatomical boundaries were identified by cross-reference between the MRI images and a reference text, "A Stereotaxic Atlas of the Rat Brain" (5th edition) (Pellegrino \& Cushman, 2005).

\section{Cerebellum Tracing}

Tracing of the cerebellum was divided into three sections: lobules 1-5 (anterior cerebellum), lobules 6-7 (posterior cerebellum) and lobules 8-10 (flocculonodular cerebellum). These groupings were chosen based both on similarity of function and to remain consistent with what has been traditionally chosen in the literature (Scott, Schumann, Goodlin-Jones, \& Amaral, 2009; Courchesne et al., 2001). The boundaries of lobules 8-10 are easily visible on the MRI scans (Figure 1A), with the exception of the anterior border as the lobules' profile shrinks on the ventral side of the cerebellum. In cases where the borders were difficult to discern, the $4^{\text {th }}$ ventricle was used as an anatomical marker as according to the literature the last of this group of lobules to be 
visible coincides with the point at which the $4^{\text {th }}$ ventricle appears largest in a sagittal slice (Figure 1B).

The boundaries of Lobules $1-5$, similar to lobules $8-10$, are clearly visible and distinct from lobules 6-7. Anteriorly, the lobules are first visible as a dark spot on the posterior wall of the cerebral aqueduct (Figure 2A). This expands slowly as the scans move posteriorly as the inferior colliculi and temporal lobes disappear. The boundary between lobules 1-5 and 6-7 is defined by the presence of the primary fissure, which divides lobule 6 dorsally and lobule 5 ventrally (Figure 2B).

Lobules 6-7 initially appear anterior and dorsal to lobules 8-10, and tracing from the posterior of the cerebellum moving forward their boundaries are extremely clear. As the boundary of lobules 8-10 migrate ventrally, as tracing moves anteriorly, lobules 6-7 eventually take over the entire cross-section of the cerebellum approximately $10-12 \mathrm{~mm}$ caudally from bregma. Some brains to be traced have their parafloccululi attached and some do not, therefore they will not be included in the tracing so as not to influence statistical analysis.

It should be noted that due to some errors in MRI scanning, only 7 SLOW and 11 FAST animals received cerebellum tracing. The MRI machine completed its scan before it reached the end of some brains, which resulted in the posterior end of the cerebellum not being scanned. The tracing of the frontal lobes and corpus callosum were unaffected.

\section{Frontal Lobe Tracing}

Tracing of the frontal lobes followed directly from the trace of the whole cerebrum. While there is no defined consensus in the literature as to the coordinates where the frontal lobe of the rat ends and the parietal lobe begins, we have chosen a point 
at approximately $3.2 \mathrm{~mm}$ posterior of bregma where the motor cortex terminates. While this is not readily visible on the MRI images due to the homogeneity of the surrounding tissue, this point conveniently coincides with the coordinates at which the optic chiasm begins to migrate dorsally from the ventral edge of the brain. Analysis has been performed and there was no significant difference between strains with respect to the point along the anterior-posterior axis at which this occurs. In both strains, the migration of the optic chiasm occurs on the $104^{\text {th }}$ slice, averaging slice 104.23 for FAST animals, 104.88 for SLOW $[\mathrm{F}(16,1)=0.041, p=0.87]$. Therefore the trace represents the wholebrain volume up to the slide on which the optic chiasm is first completely internalized in

the brain (Figure 3). Tracing were performed independently on each hemisphere to allow for rapid statistical comparison.

\section{Corpus Callosum Tracing}

The corpus callosum appears on the MRI images as a very clear, lightly coloured area compared to the surrounding brain structures. Its boundaries are extremely well defined and there were no complications in its tracing.

\section{Statistical Image Sampling}

Following the tracing of each brain structure, the Analyze 8.1 software is able to render a 3 dimensional image of the structure, at which point any major flaws or omissions become readily apparent. Following this, the program is able to sample each image individually and, after being provided with the thickness of each slice and the scale of each voxel (measure of area traced), is able to return the area of each structure on any 
given slice as well as calculate the total volume of each structure. The raw data are then transferred to a spreadsheet for statistical analysis.

\section{Stereology}

To determine whether significant differences exist between the FAST and SLOW strains on a cellular level within the cerebellum, 8 male, adult rat cerebelli from each strain were sectioned, stained and analyzed using optical stereological methods using the optical fractionator technique; this involves randomly generating three dimensional counting frames within the sample tissue and counting only the cells contained within these spaces. The results of these counts are then used to estimate the total cell population for the region of interest.

\section{Histology}

8 FAST and 8 SLOW adult males aged 4-5 months were perfused using the same method described above and their brains were extracted and stored in a $4 \%$ paraformaldehyde solution. Each brain was bisected down the midline and the left hemisphere was used for stereology, while the right hemispheres were preserved in paraformaldehyde for 3-4 months. Each hemisphere was wrapped in cloth and put through a series of Clearene and alcohol baths to clean and dehydrate the tissue. Each alcohol bath lasted 90 minutes each at concentrations of $60 \%, 70 \%, 80 \%, 95 \%$ and 3 washes of $100 \%$. This was followed by three $100 \%$ Clearene baths lasting one hour each. Following this, they were bathed in liquid paraffin and subsequently encased in paraffin blocks for sectioning. One SLOW brain was damaged during the embedding procedure and was omitted from the experiment. Sagittal sections were cut from the tissue at a 
thickness of $100 \mu \mathrm{m}$ and affixed to microscope slides, resulting in an average of 38 slices per hemisphere. There was no significant difference in the number of slices between the two strains.

One third of the cerebellar slices were sampled for slicing by randomly choosing a number between 1 and 3 . This became the starting section and every $3^{\text {rd }}$ slice was counted. This interval was chosen to strike a balance between the efficiency of the experiment and the accuracy of the generated data. This resulted in approximately 13-14 sections being used for stereology from each animal. These sections were rehydrated through alcohol and water baths and stained for 60 minutes in a 4:1 dilution of Gill's Hematoxylin I (Surgipath). Sections were rinsed in warm water and dehydrated again in alcohol baths before being coverslipped for microscopy.

\section{Cell Counting}

In accordance with previous studies (Schmitz et al., 2005; Larsen, Skalicky, \& Viidik, 2000), Purkinje cells were counted using a 40X magnification objective using an Olympus BX51 light microscope attached to a desktop computer running StereoInvestigator version 7 . Using the software interface at low magnification, the molecular layer, granule cell layer and white matter layers were traced out using the mouse and saved as independent structures (Figure 5). Using the fine focus, the thickness of each section was measured to be, on average, $44.33 \mu \mathrm{m}$. This difference in thickness was expected from the staining, dehydrating and mounting procedures (Schmitz et al., 2005 ) and was compensated for by the software (which knows the original thickness was $100 \mu \mathrm{m})$.

To count Purkinje cells, it was necessary to create virtual counting frames, three dimensional boxes scattered randomly throughout the molecular layer in which cells are 
counted and the results are extrapolated to estimate the total cell population (Figure 4). Approximately 30 of these counting frames, $30 \mu \mathrm{m} \times 30 \mu \mathrm{m}$ in area and $15 \mu \mathrm{m}$ thick, were generated per section. To protect against damaged tissue and incomplete cells in a given section, a $5 \mu \mathrm{m}$ guard zone was placed at the top of the slice where the counting frames could not be placed and therefore cells could not be counted. After merging sections from the same brain into a single structure, StereoInvestigator was able to estimate the total cell population in the entire hemisphere as well as the volume of each structure overall.

\section{Statistical Analysis}

Data concerning the volumes of structures were compiled in the imaging software and transferred from Analyze 8 to a spreadsheet for analysis using the Statsview software package. Raw volume data was standardized according to animal weight and age, using each as a covariate. Comparisons between structures were performed using one-way analysis of variance (ANOVA) with the strain (FAST vs. SLOW) serving as betweensubjects variable and analysis of any interaction effects between structures was assessed using correlation matrices. The same statistical processes were used to analyze data gathered from stereology, however results could not be standardized to animal weight as these data were not available. 
Figure 1: MRI images of cerebellar lobules 7-10, numbered in white. Posteriorly, the boundaries between lobules (dark bands) are clearly visible (A), whereas in more anterior regions there is less definition as lobule 5 becomes more prominent and the $4^{\text {th }}$ ventricle reaches its maximum area (lighter area between cerebellum and brainstem) (B). 

Figure 2: MRI images of the cerebellum. (A) represents the most anterior portion of the cerebellum, visualized as a gray spot visible in the 3rd ventricle. Red circle represents the area where the cerebellum first becomes visible, under the $3^{\text {rd }}$ ventricle. (B) demonstrates the clarity of the primary fissure, the black horizontal line separating cerebellar lobule 5 below from lobule 6 above (circled). 


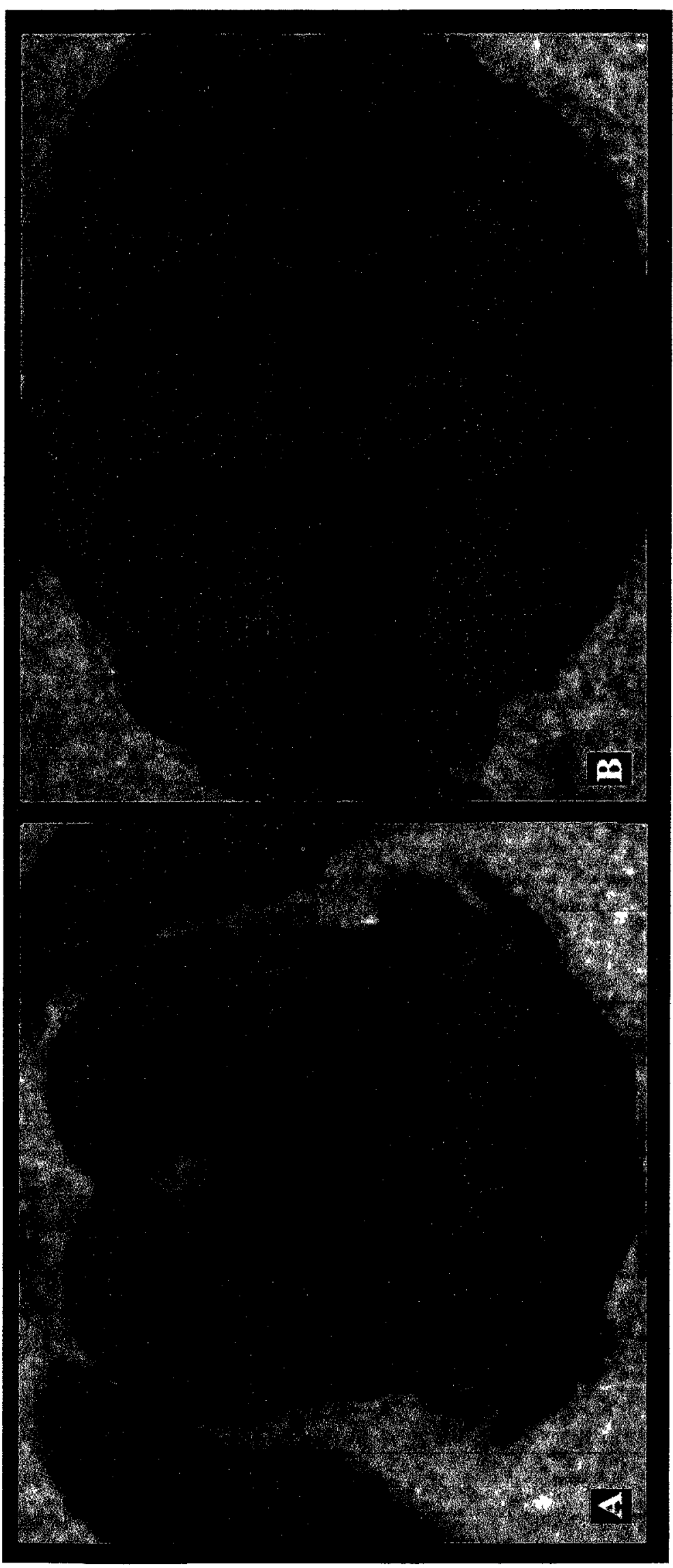


Figure 3: Migration of the optic tracts as the MRI progresses in a posterior direction in the coronal plane. Images A and B show the optic tracts separating (dark tissue circled in B) from the chiasm (dark tissue circled in A), while image $C$ represents the cut-off point for frontal lobe tracing, when the tracts are about to be fully enveloped in the temporal lobe. In image D the optic tracts are fully enveloped. 


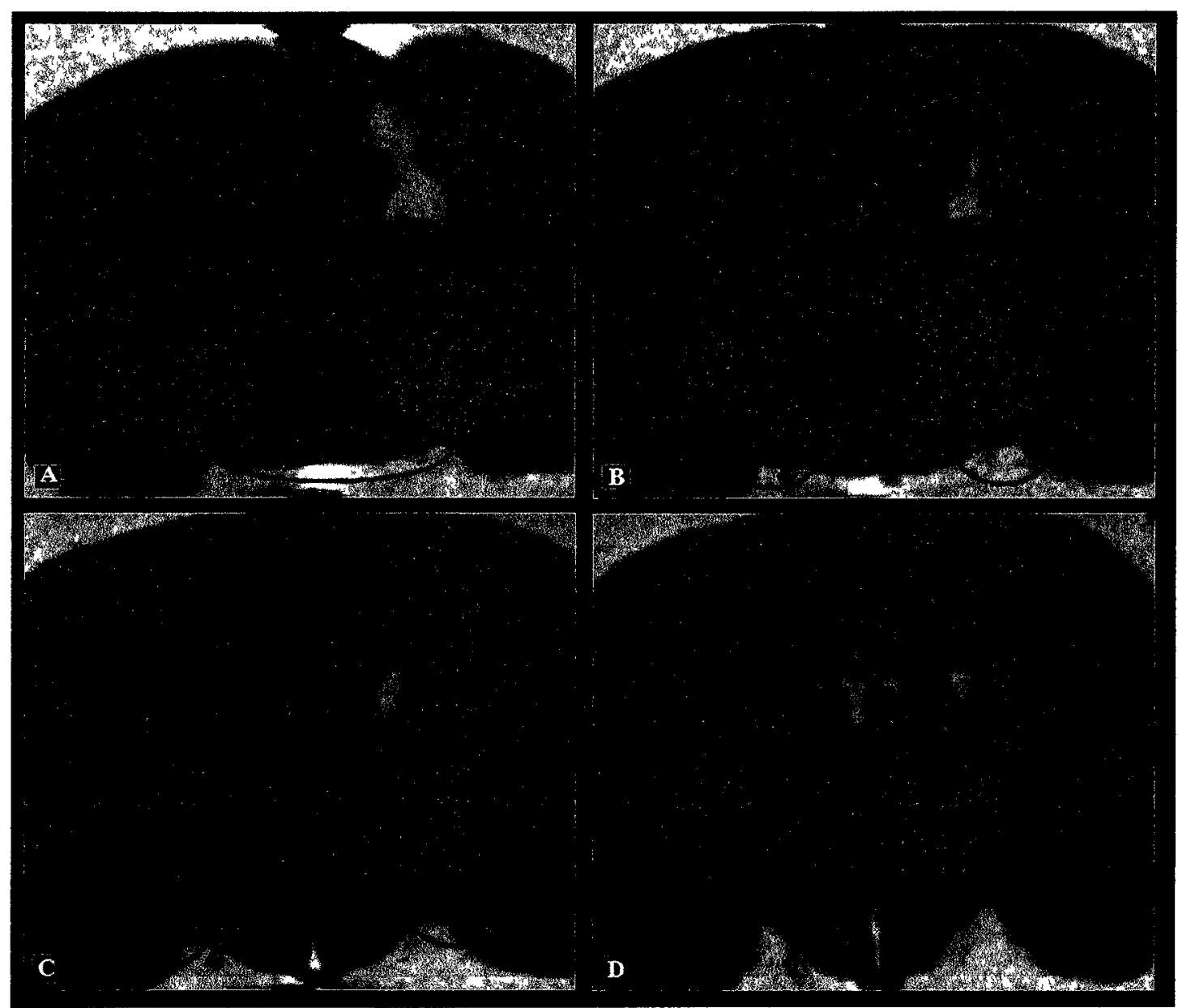


Figure 4: Stereological counting frame used to estimate Purkinje cell population. Only cell bodies within the marked box are counted and only if they do not touch the red boundaries. Counting frame dimensions were $30 \mu \mathrm{m} \times 30 \mu \mathrm{m}$ and $15 \mu \mathrm{m}$ deep into the tissue. Asterisks $\left({ }^{*}\right)$ mark Purkinje cell bodies counted. 


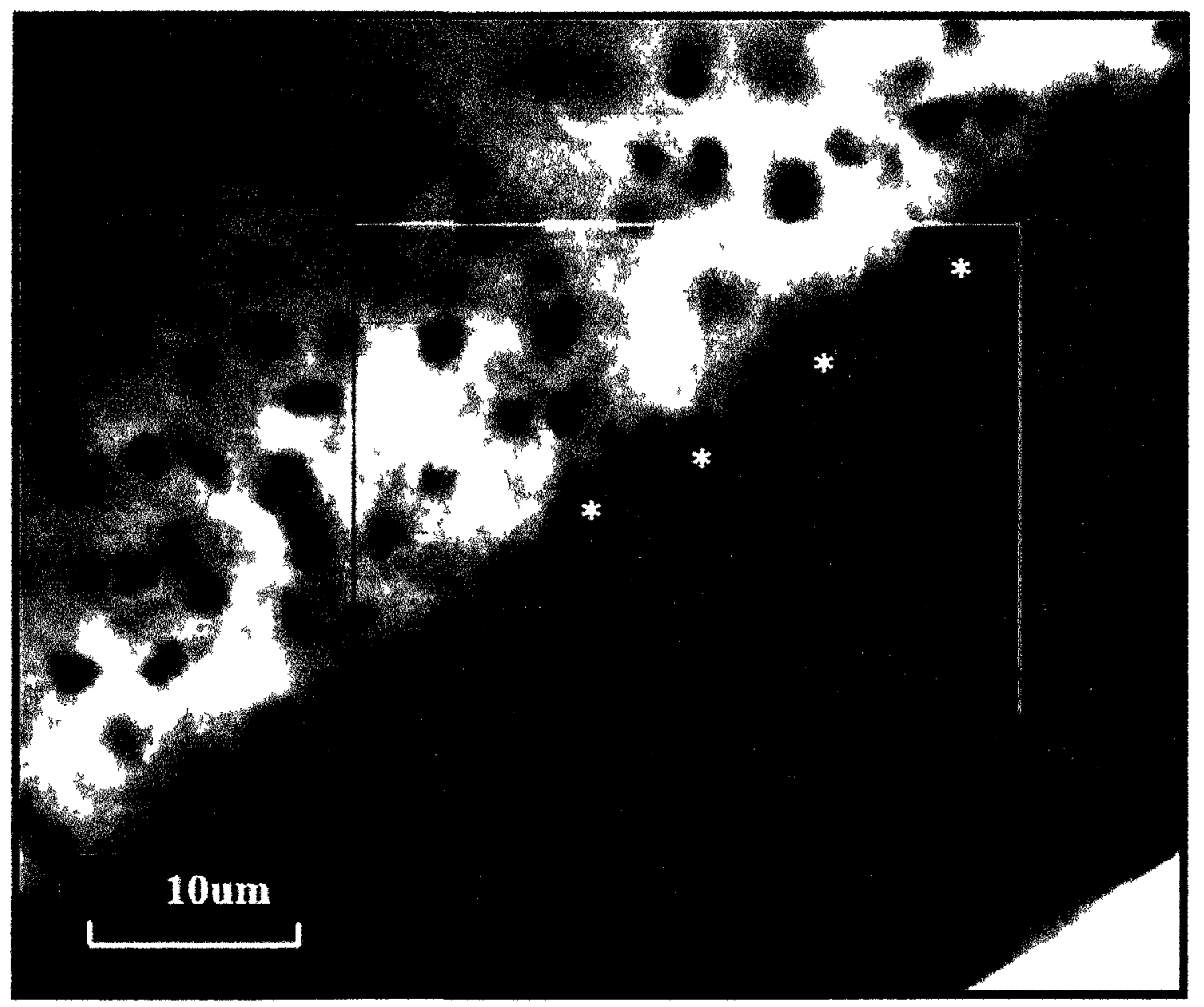


Figure 5: Volume estimation of cell layers in the cerebellum was performed by tracing each layer of interest using the StereoInvestigator software package. In this image of the posterior cerebellum, the outer glial cell layer (GL) is marked by the red outline. The Purkinje cell layer (PL) is marked as the darker shaded space between the red and green trace lines. Finally, the white matter layer at the interior of the cerebellum is contained entirely within the green trace. 


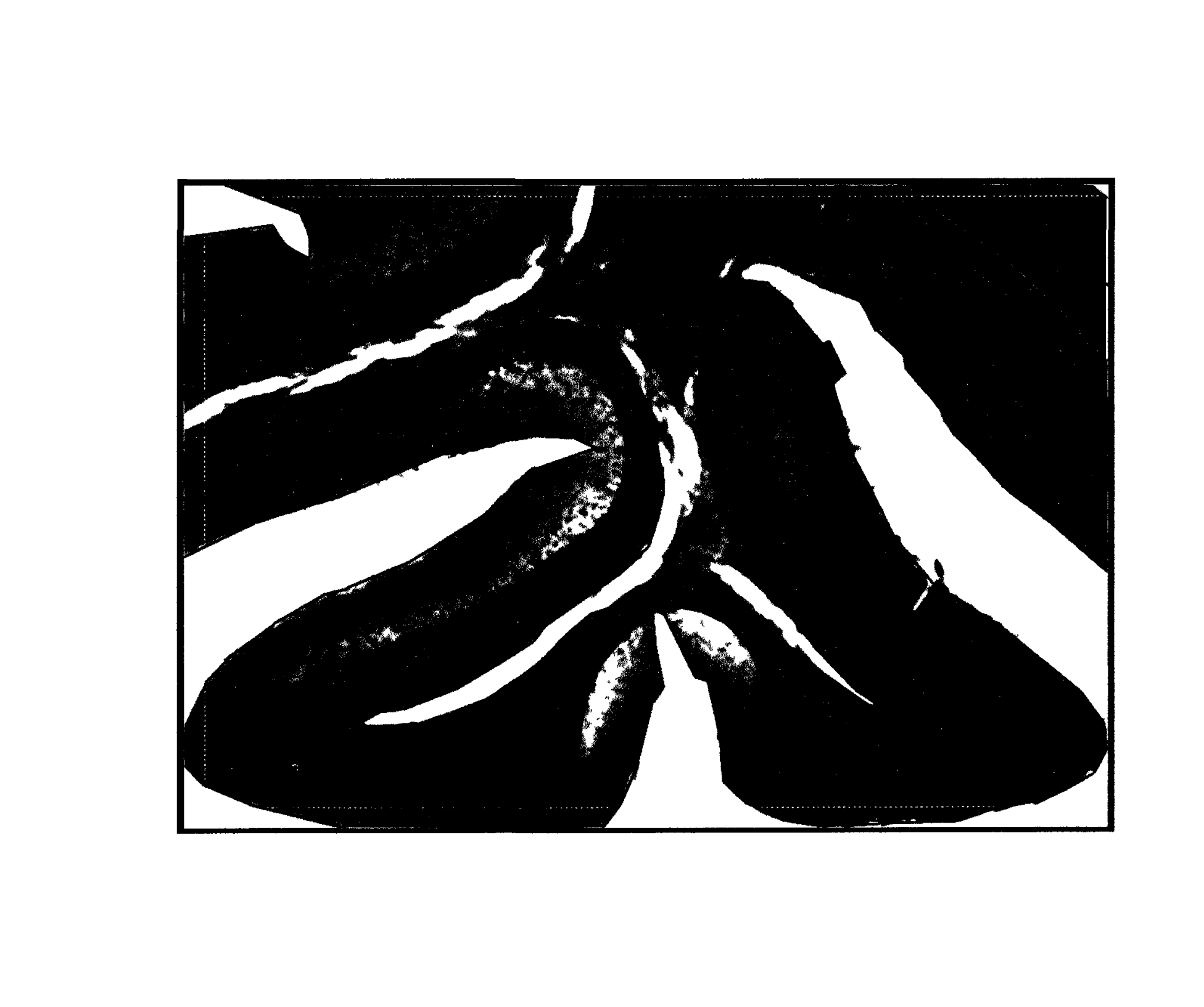




\section{Results}

\section{Magnetic Resonance Imaging}

\section{Frontal Lobe/Cerebrum}

In tracing the frontal lobes of the FAST and SLOW rats (Table 1), it was found that there was no significant difference in total hemispheric volume between the strains $[\mathrm{F}(1,21)=0.693, p=.415$, Figure 6$]$; the FAST strain had an average frontal lobe volume (combined hemispheres) of $374.32 \mathrm{~mm}^{3}$ while the SLOW animals measured $366.40 \mathrm{~mm}^{3}$. Furthermore, there were no significant differences found in the volumes of the left and right hemispheres of the frontal lobe for either strain [SLOW $\mathrm{F}(1,16)=0.001, p=.970$, $\operatorname{FAST} \mathrm{F}(1,16)=1.383, p=.230]$. Three dimensional reconstruction of the cerebrum revealed no visible differences (an example of this reconstruction can be seen in Figure 7) in overall morphology. There was no significant difference between strains in terms of total cerebral volume $[\mathrm{F}(1,21)=3.56, p=.072]$, with the FAST strain having an average volume of $1434.21 \mathrm{~mm}^{3}$ compared to $1381.04 \mathrm{~mm}^{3}$ in the SLOWs.

\section{Corpus Callosum}

Tracing of the corpus callosum (Table 2, Figure 8) revealed that the FAST strain had a volume $10 \%$ higher $[\mathrm{F}(1,21)=9.842, p=.005]$ when compared with the SLOW strain. FAST animals had an average volume of $87.29 \mathrm{~mm}^{3}$ while SLOW animals averaged $79.27 \mathrm{~mm}^{3}$. A three dimensional reconstruction of the corpus callosum can be seen in Figure 9. Note that the white bars are of equal length, highlighting the difference between FAST and SLOW strains. In terms of dimensions, the thickness of the corpus callosum in the transverse plane did not differ significantly between strains $[\mathrm{F}(21,1)=$ $1.414, p=.381]$, as measured by the number of MRI images in which the structure was represented, however the length of the corpus callosum along the coronal plane did differ 
significantly. On average the FAST rats showed corpus callosum tissue in 126 of 230 slices, with each slice having a thickness of $0.45 \mathrm{~mm}$, compared to an average length of 108 slices for SLOW rats with a thickness of $0.45 \mathrm{~mm}[\mathrm{~F}(21,1)=7.244, p=0.013]$. It should be noted that these results persisted when the corpus callosum volume was standardized as a percentage of total cerebral volume $[\mathrm{F}(1,21)=7.83, p=0.011]$, with the FAST strain still being, on average, 9.2\% larger than their SLOW counterparts. 
Table 1: Each hemisphere of the frontal lobe was traced independently, and there were no significant differences found between the left hemisphere (LH) and right hemisphere $(\mathrm{RH})$ within each strain. There was also no significant difference between strains with respect to the cut-off point where measurement stopped $[\mathrm{F}(16,1)=0.041, p=0.87]$.

\begin{tabular}{cccccc} 
FAST & Cutoff Slice & \multicolumn{2}{c}{ Volume $\left(\mathrm{mm}^{3}\right)$} & \multicolumn{2}{c}{ Average Slice Area $\left(\mathrm{mm}^{3}\right)$} \\
\hline $\mathrm{n}=14$ & & LH & RH & LH & RH \\
\hline Sam107x & T-102 & 387.82 & 350.81 & 97.23 & 97.16 \\
Sam25x & T-103 & 345.17 & 361.39 & 93.77 & 95.23 \\
Sam510x & T-102 & 363.56 & 369.19 & 95.21 & 96.80 \\
Sam86x & T-96 & 366.75 & 391.73 & 95.14 & 92.27 \\
Sam95x & T-108 & 362.53 & 363.69 & 99.53 & 96.58 \\
F1rat7x & T-136(94)* & 329.52 & 384.52 & 108.67 & 107.97 \\
F2rat6x & T-97 & 362.69 & 362.77 & 93.92 & 92.93 \\
F3rat6x & T-122 & 391.84 & 443.82 & 102.39 & 100.68 \\
F4rat6x & T-121 & 403.09 & 431.16 & 112.13 & 108.85 \\
F5rat6x & T-94 & 393.66 & 404.59 & 120.62 & 114.31 \\
Sam15x & T-107 & 377.22 & 373.55 & 85.10 & 88.42 \\
Sam35x & T-113 & 355.15 & 358.98 & 94.39 & 97.66 \\
Sam45x & T-96 & 367.53 & 375.35 & 90.25 & 93.50 \\
Sam75x & T-97 & 356.23 & 346.77 & 103.74 & 104.36 \\
\hline Average & 104.23 & 368.77 & 379.88 & 99.44 & 99.05 \\
\hline Sig. & & 0.230 & & 0.831 \\
\end{tabular}

\begin{tabular}{cccccc}
$\mathbf{n}=9$ & & LH & RH & LH & RH \\
\hline Sam116x & T-96 & 314.87 & 348.51 & 98.32 & 95.59 \\
Sam125x & T-98 & 387.15 & 360.35 & 95.06 & 95.98 \\
Sam145x & T-104 & 386.33 & 405.48 & 90.90 & 89.70 \\
Sam15 low rez & T-113 & 387.31 & 401.37 & 114.02 & 114.44 \\
Sam176x & T-101 & 356.94 & 363.67 & 94.32 & 93.88 \\
Sam197x & T-80 & 345.88 & 341.02 & 92.60 & 93.13 \\
S1rat9x & T-124 & 380.19 & 322.39 & 100.32 & 99.95 \\
S2rat5x & T-108 & 383.14 & 390.11 & 98.45 & 99.80 \\
Sam186x & T-109 & 357.91 & 362.55 & 82.82 & 82.21 \\
\hline Average & 104.88 & 366.64 & 366.16 & 96.31 & 96.08 \\
\hline Sig. & & 0.970 & & 0.954 &
\end{tabular}


Figure 6: Between-strain comparison of frontal lobe volume yielded no significant difference between FAST and SLOW animals $[\mathrm{F}(1,21)=0.693, p=.415]$. 
400.00

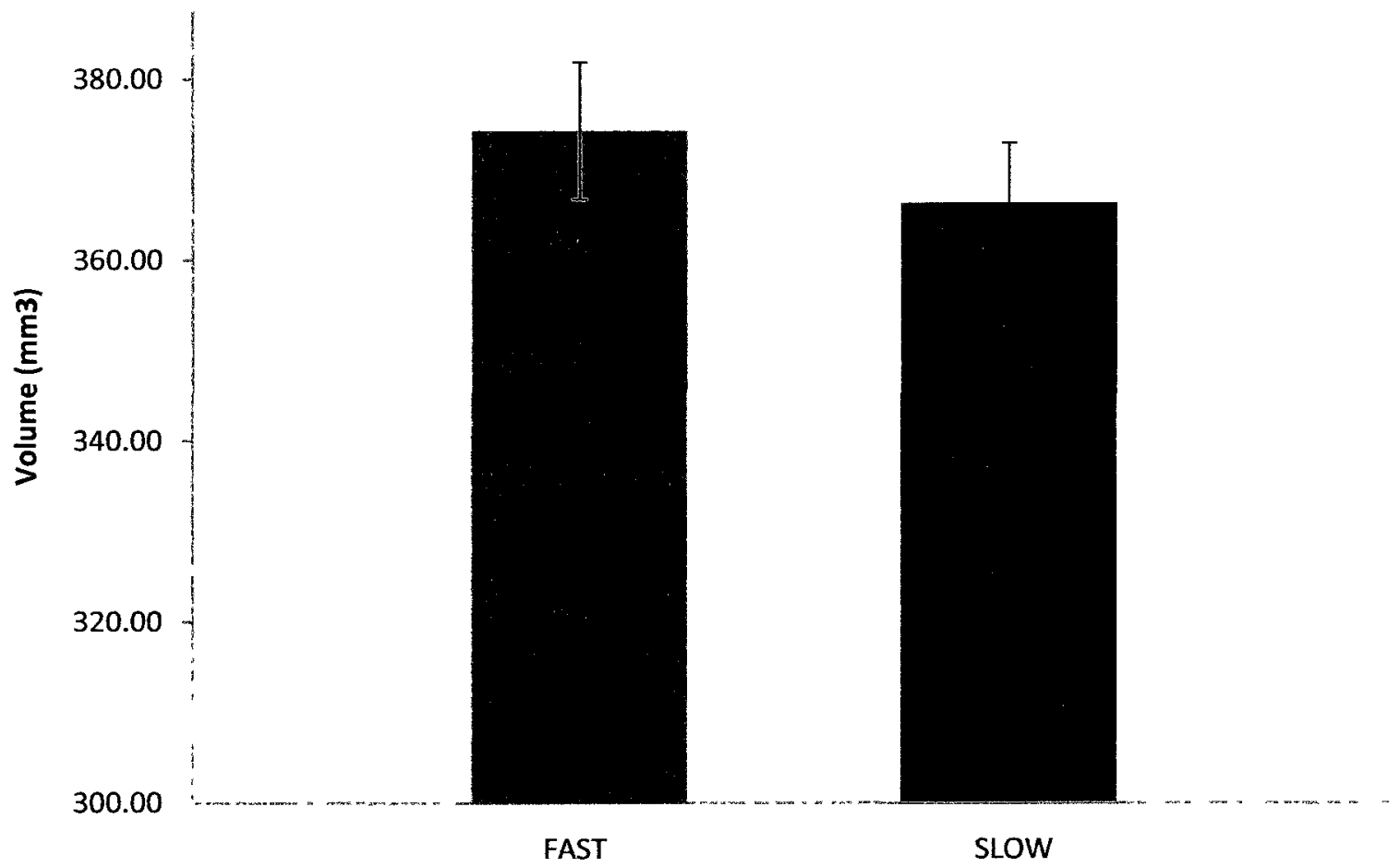


Figure 7: Three dimensional reconstruction of the cerebral hemispheres in both FAST and SLOW animals. There were no significant differences found with respect to volume or overall morphology. 


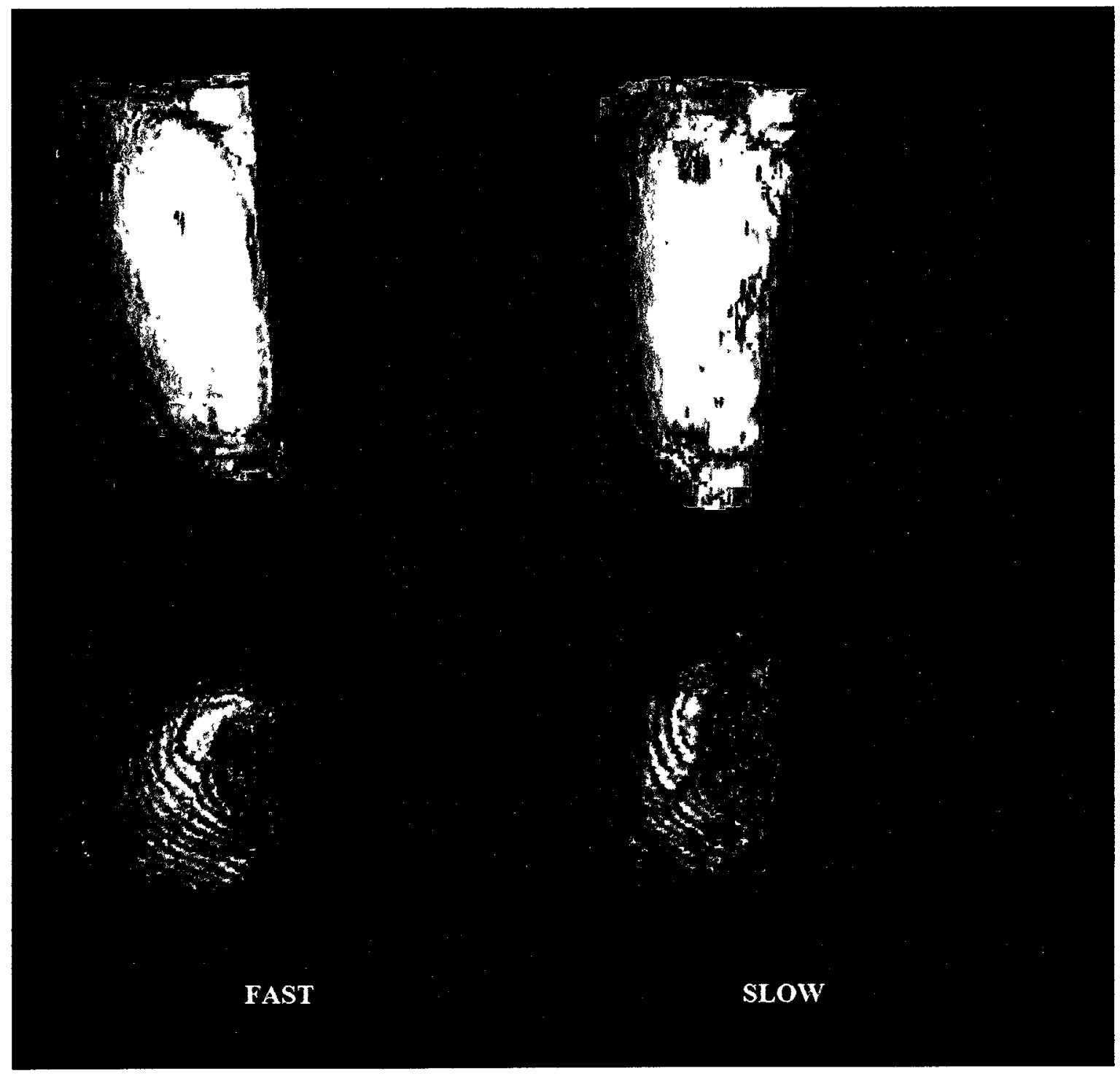


Table 2: Volume of the corpus callosum in FAST and SLOW rats. FAST rats were found to have significantly larger volumes than their SLOW counterparts $[\mathrm{F}(1,21)=9.842, p=$ $.005]$.

\begin{tabular}{cccc}
$\begin{array}{c}\text { FAST } \\
\mathrm{n}=14\end{array}$ & \multicolumn{2}{c}{ Volume $\left(\mathrm{mm}^{3}\right)$} & $\begin{array}{c}\text { SLOW } \\
\mathrm{n}=9\end{array}$ \\
\hline Sam107x & 90.92 & 70.00 & Sam116x \\
Sam $25 \mathrm{x}$ & 81.67 & 82.85 & Sam125x \\
Sam510x & 88.28 & 74.09 & Sam145x \\
Sam86x & 91.34 & 75.87 & Sam15 low rez \\
Sam95x & 93.32 & 79.27 & Sam176x \\
F1rat7x & 81.84 & 78.96 & Sam197x \\
F2rat6x & 81.19 & 83.46 & S1rat9x \\
F3rat6x & 86.08 & 79.59 & S2rat5x \\
F4rat6x & 81.34 & 89.32 & Sam186x \\
F5rat6x & 95.68 & 79.27 & Average \\
Sam15x & 95.03 & & \\
Sam35x & 84.85 & & \\
Sam45x & 76.61 & & \\
Sam75x & 93.88 & & \\
\hline Average & 87.29 & & \\
\hline Sig. & \multicolumn{2}{c}{0.005} &
\end{tabular}


Figure 8: Corpus callosum volume in FAST vs. SLOW strains. FAST animals were found to be $10 \%$ larger than the SLOWs. 


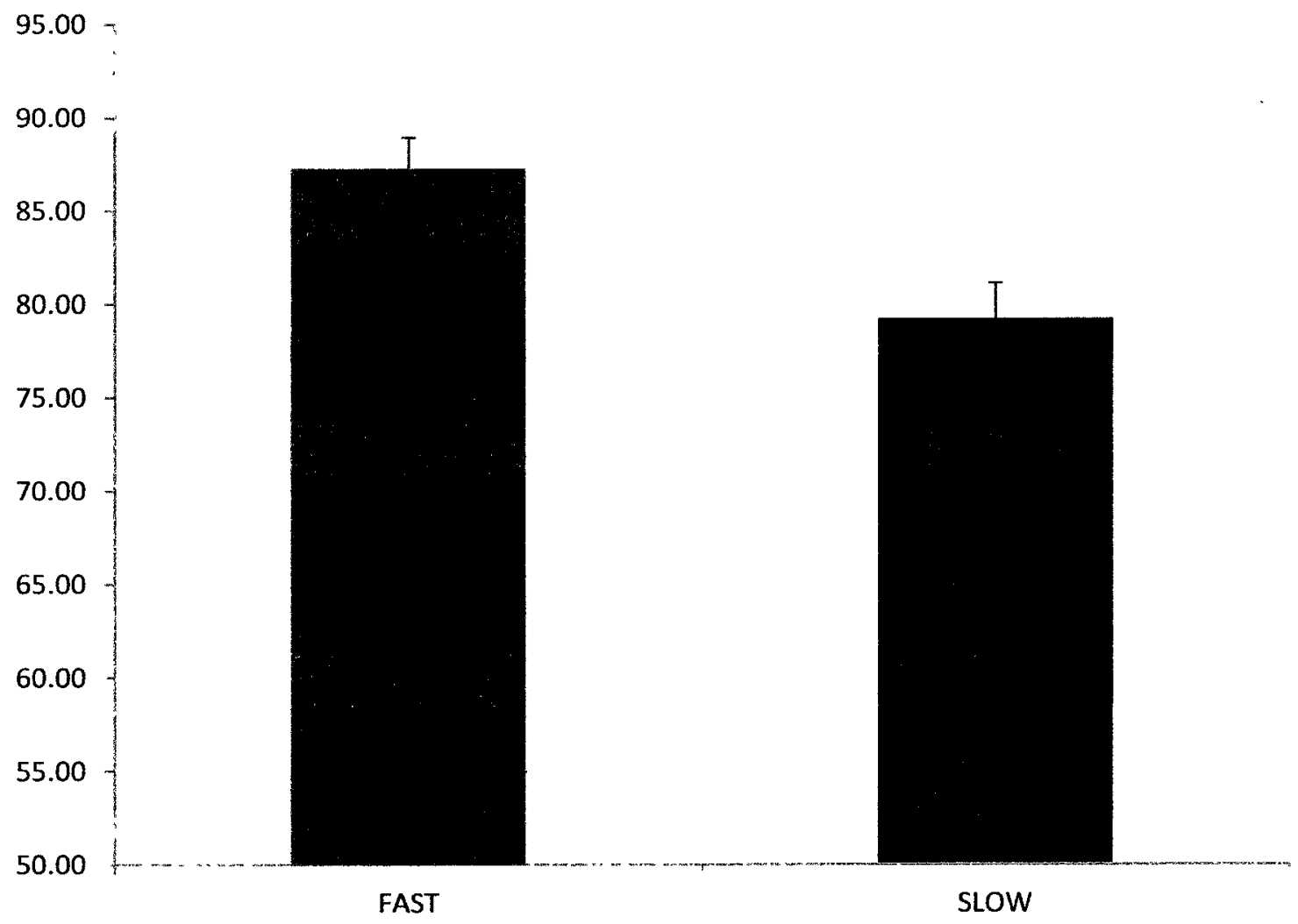


Figure 9: Three dimensional reconstruction of the corpus callosum in FAST (left) and SLOW (right) rats. There does seem to be a marked difference in the shape of the corpus callosum, both in terms of horizontal length (top. white bars are of equal length) and the degree to which the ventral portion of the corpus callosum (external capsule) hooks inwards. 


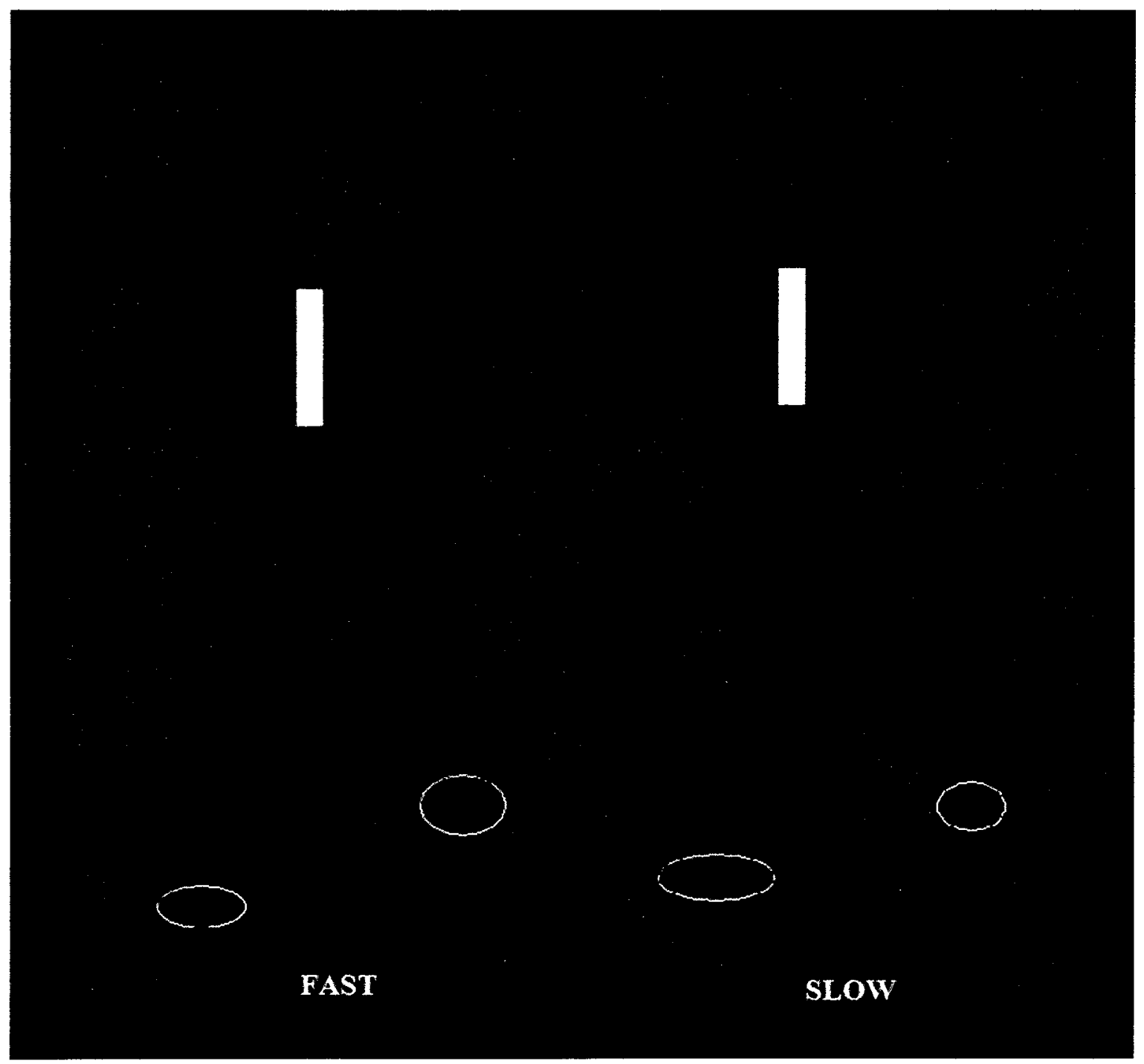




\section{Cerebellum}

It was found that the anterior cerebellum was significantly larger in the FAST strain when compared to the SLOW strain $[\mathrm{F}(16,1)=9.732, p=.007]$. In the posterior cerebellum, it was found that the opposite was true, i.e., the SLOW strain volume was significantly larger than that found in FAST rats $[\mathrm{F}(16,1)=9.732, p=.013]$. In the posterior cerebellum (lobules 8-10), the FAST strain was found to be slightly larger in volume than the SLOWs, but not to the point of statistical significance $[\mathrm{F}(16,1)=3.270$, $p=.089]$. When cerebellar regions were combined, the total cerebellum volume did not differ significantly between the two strains $[\mathrm{F}(16,1)=0.052, p=.822]$. These results are summarized in Table 3 and Figure 10.

\section{Correlations}

Within each strain, the correlation coefficients were calculated between all traced structures (Tables 4 \& 5). In the FAST strain, the volume of each individual division of the cerebellum correlated significantly with the total combined volume of the cerebellum (Table 4), while in the SLOW strain, no such correlations were found. Both strains showed very high positive correlation between total cerebellar volume and total frontal lobe volume $(\mathrm{FAST} \mathrm{r}=.960, p<.001 ;$ SLOW $\mathrm{r}=.996, p<.001)$. Finally, there was a significant positive correlation recorded between the volume of the posterior cerebellum and the volume of the corpus callosum in SLOW animals $(\mathrm{r}=.725, p=.002)$. 
Table 3: MRI trace volume of cerebellar sub-regions: the anterior cerebellum (Lobules 15), posterior cerebellum (Lobules 6-7) and the flocculonodular cerebellum (Lobules 810). Total volume is a sum total of the three sub-regions. All volumes are in $\mathrm{mm}^{3}$.

\begin{tabular}{|c|c|c|c|c|}
\hline FAST & Lobules 1-5 & Lobules 6-7 & Lobules 8-10 & Total Volume \\
\hline $\mathrm{n}=11$ & & & & \\
\hline Sam107x & 130.61 & 87.80 & 55.46 & 273.87 \\
\hline $\operatorname{Sam} 25 x$ & 152.22 & 61.84 & 59.50 & 273.56 \\
\hline Sam 510x & 142.80 & 80.98 & 64.18 & 287.96 \\
\hline Sam86x & 137.31 & 64.56 & 53.99 & 255.86 \\
\hline Sam95x & 125.09 & 64.25 & 52.23 & 241.57 \\
\hline fl rat $-7 x$ & 133.88 & 68.44 & 55.92 & 258.24 \\
\hline f2rat-6x & 133.04 & 62.92 & 53.61 & 249.57 \\
\hline $\operatorname{Sam} 75 x$ & 128.65 & 67.81 & 58.33 & 254.79 \\
\hline $\operatorname{Sam} 45 x$ & 138.01 & 65.72 & 59.76 & 263.49 \\
\hline $\operatorname{Sam} 15 x$ & 134.60 & 59.87 & 51.23 & 245.70 \\
\hline f5rat-6x & 140.55 & 62.33 & 56.86 & 259.74 \\
\hline Average & 136.07 & 67.87 & 56.46 & 260.40 \\
\hline \multicolumn{5}{|l|}{ SLOW } \\
\hline \multicolumn{5}{|l|}{$\mathrm{n}=7$} \\
\hline $\operatorname{Sam} 125 \mathrm{x}$ & 125.86 & 87.63 & 49.38 & 262.87 \\
\hline $\operatorname{Sam} 176 x$ & 118.66 & 80.03 & 53.77 & 252.46 \\
\hline $\operatorname{Sam} 197 x$ & 133.54 & 86.00 & 52.44 & 271.98 \\
\hline Sam116x & 123.37 & 73.18 & 52.93 & 249.48 \\
\hline Sam $145 x$ & 127.32 & 88.76 & 56.44 & 272.52 \\
\hline S2rat-5x & 122.44 & 69.10 & 54.77 & 246.31 \\
\hline $\operatorname{Sam} 186 x$ & 130.97 & 71.23 & 55.21 & 257.41 \\
\hline Average & 126.02 & 79.42 & 53.56 & 259.00 \\
\hline Sig. & $0.007^{*}$ & $0.013 *$ & 0.089 & 0.822 \\
\hline
\end{tabular}


Figure 8: Between-strain comparison of cerebellar sub-region volume. FAST animals had significantly larger anterior cerebellum (Lobules 1-5), while SLOW animals showed significantly larger posterior cerebellum (Lobules 6-7). Total cerebellum volume was not significantly different between strains. 


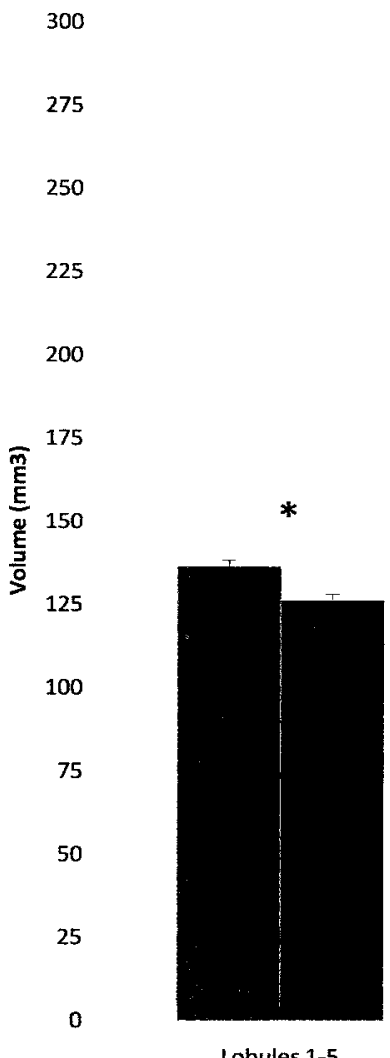

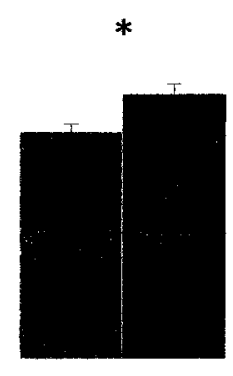

Lobules 6-7

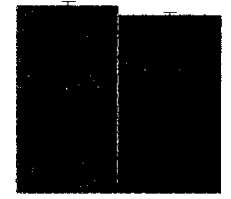

Lobules 8-10

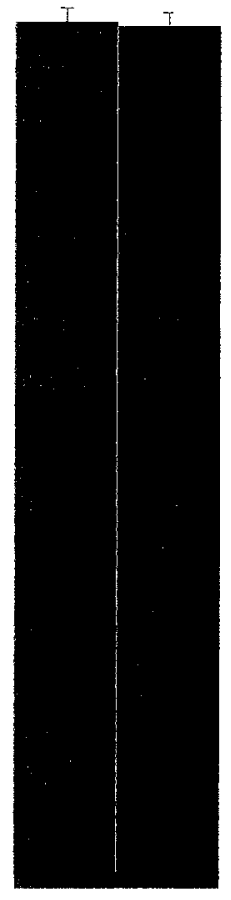

Total Volume
- FAST

- SLOW 
Table 4: Correlations between structure volumes in the FAST rat strain. Significant correlations are marked with an asterisk (*). Structures listed include: Anterior cerebellum (L1-5), posterior cerebellum (L6-7), flocculonodular cerebellum (L8-10), total cerebellar volume (CB), frontal lobes (FL) and corpus callosum (CC).

\begin{tabular}{l|cccccc}
$\mathrm{n}=14$ & & & & & \\
FAST & L1-5 & L6-7 & L8-10 & CB & FL & CC \\
\hline L1-5 & 1.000 & & & & & \\
L6-7 & -0.132 & 1.000 & & & & \\
L8-10 & $0.573^{*}$ & 0.402 & 1.000 & & & \\
CB & $0.619^{*}$ & $0.675^{*}$ & $0.845^{*}$ & 1.000 & & \\
FL & 0.109 & -0.123 & -0.176 & $0.960^{*}$ & 1.000 & \\
CC & -0.275 & 0.247 & 0.282 & 0.085 & 0.231 & 1.000
\end{tabular}


Table 5: Correlations between structure volumes in the SLOW rat strain. Significant correlations are marked with an asterisk (*). Structures listed include: Anterior cerebellum (L1-5), posterior cerebellum (L6-7), flocculonodular cerebellum (L8-10), total cerebellar volume (CB), frontal lobes (FL) and corpus callosum (CC).

\begin{tabular}{l|cccccc}
$\mathrm{n}=9$ & & & & & \\
SLOW & L1-5 & L6-7 & L8-10 & CB & FL & CC \\
\hline L1-5 & 1.000 & & & & & \\
L6-7 & -0.145 & 1.000 & & & & \\
L8-10 & -0.001 & -0.322 & 1.000 & & & \\
CB & -0.140 & 0.172 & 0.448 & 1.000 & & \\
FL & -0.145 & 0.212 & 0.366 & $0.996^{*}$ & 1.000 & \\
CC & -0.083 & -0.644 & $0.725^{*}$ & 0.028 & -0.044 & 1.000
\end{tabular}




\section{Stereology}

\section{Purkinje cells}

The number of Purkinje cells in the cerebellum was estimated for each strain by using stereology and an optical fractionator. The average number of Purkinje cells counted in the SLOW strain was 903.71 and in the FAST strain was 781.13 (Figure 11). The counts between strains were found to be significantly different $[\mathrm{F}(13,1)=6.880, p=$ 0.021]. Using StereoInvestigator 7, the software calculated that the total population of Purkinje cells in the entire cerebellum was approximately $1.21 \times 10^{5}$ in the SLOW strain and $1.04 \times 10^{5}$ in the FAST strain. This represents a $14 \%$ difference in the total population when comparing FAST to SLOW rats.

\section{Cerebellar Layer Volumes}

In addition to counting Purkinje cells, the molecular layer (included with Purkinje cell layer), granule cell layer and white matter layers of the cerebellum were analyzed to determine if there was any difference in their volumes between strains. The molecular layer was found to be larger in the SLOW strain by $23.6 \%[\mathrm{F913,1})=7.767, p=.015]$, while the granule cell layer showed no significant difference between strains $[F(13,1)=$ $1.417), p=0.255]$. A significant difference was found in the white matter layer, with the average volume in the FAST rats being $25.0 \%$ higher than rats from the SLOW strain.

When combined, the total volume of the cerebellum encompassing all three cell layers did not significantly differ between strains $[\mathrm{F}(13,1)=0.095, p=.763]$. These statistics are representative of the adjusted volume, an estimate generated by StereoInvestigator 7 of the total cerebellar volume (left hemisphere only) accounting for a loss of tissue volume due to dehydration and histological procedures. 
Figure 9: A significant difference was found between strains when Purkinje cell populations were counted. FAST animals were found to have $14 \%$ fewer Purkinje cells than their SLOW counterparts. Note this figure represents the actual number of cells counted/ 


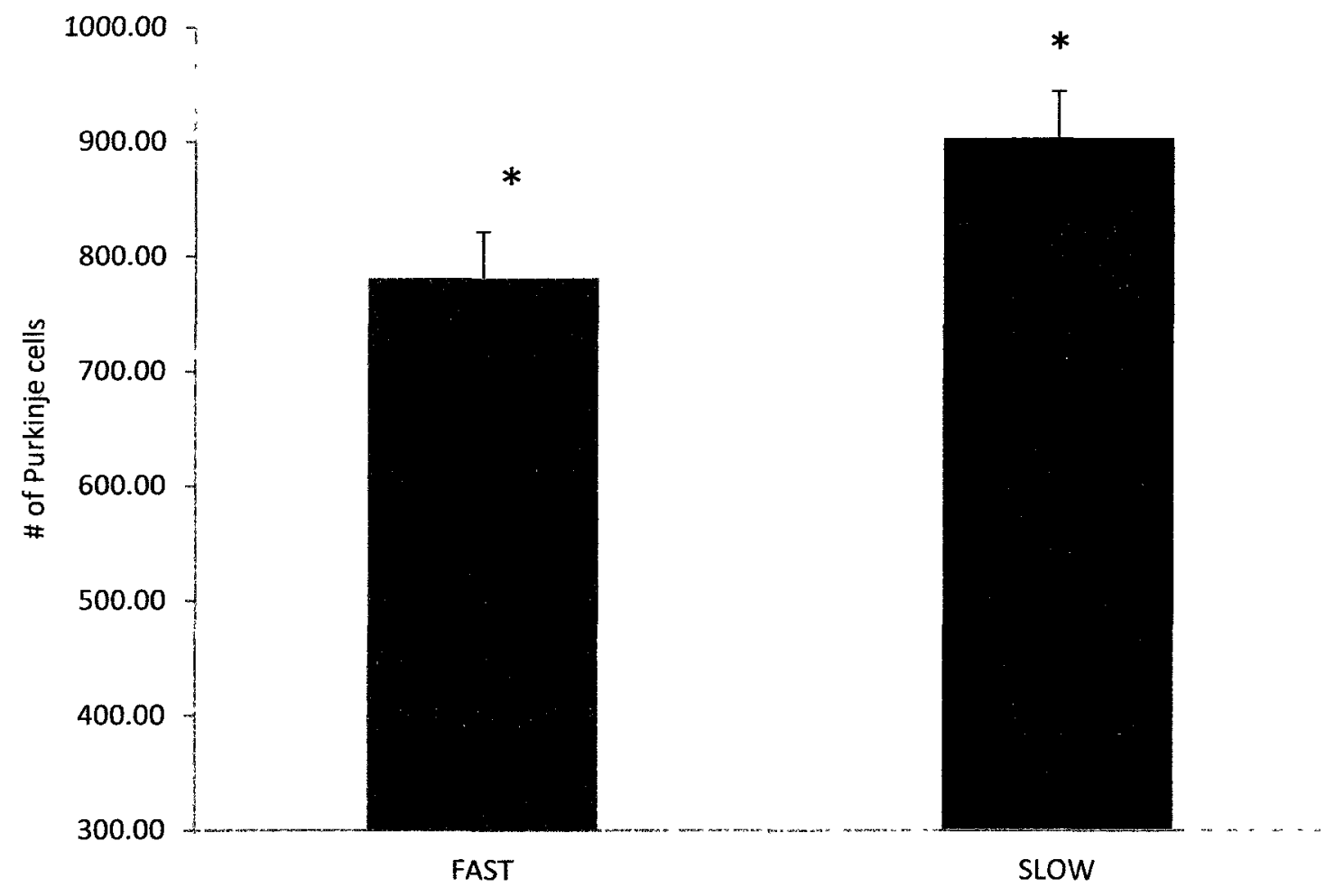


Table 6: Tissue volume of cerebellar cell layers in the FAST and SLOW rat strains.

Layers that were measured include the molecular/Purkinje cell layer (ML), glial cell layer (GL), white matter layer (WM) and the summed total cerebellar volume (CB volume). To account for tissue shrinkage during histology and coverslipping, the adjusted volume is a best estimate of the original cerebellar volume. Reported values are in $\mathrm{mm}^{3}$.

\begin{tabular}{|c|c|c|c|c|c|}
\hline $\mathrm{n}=8$ & ML volume & GL volume & WM volume & CB volume & Adj. volume \\
\hline FAST 1 & 20.64 & 16.03 & 30.43 & 67.1 & 196.47 \\
\hline FAST 2 & 22.91 & 17.22 & 23.38 & 63.51 & 179.77 \\
\hline FAST 3 & 27.58 & 21.84 & 30.14 & 79.56 & 235.77 \\
\hline FAST 4 & 23.7 & 20.28 & 27.56 & 71.54 & 198.28 \\
\hline FAST 5 & 26.25 & 14.52 & 31.59 & 72.36 & 218.03 \\
\hline FAST 6 & 19.66 & 13.78 & 32.2 & 65.64 & 187.2 \\
\hline FAST 7 & 21.41 & 18.85 & 27.91 & 68.17 & 203.13 \\
\hline \multirow[t]{2}{*}{ FAST 8} & 26.17 & 20.81 & 30.71 & 77.69 & 230.8 \\
\hline & 23.54 & 18.19 & 29.07 & 70.8 & 207.57 \\
\hline \multicolumn{6}{|l|}{$n=7$} \\
\hline SLOW 1 & 25.52 & 18.56 & 27.5 & 71.58 & 218.77 \\
\hline SLOW 2 & 25.09 & 15.31 & 20.89 & 61.29 & 172.74 \\
\hline SLOW 3 & 32.62 & 24.33 & 22.45 & 79.4 & 228.74 \\
\hline SLOW 4 & 30.69 & 22.51 & 24.34 & 77.54 & 217.01 \\
\hline SLOW 5 & 37.56 & 23.02 & 22.6 & 83.18 & 236.85 \\
\hline SLOW 6 & 25.87 & 20.63 & 22.29 & 68.79 & 209.77 \\
\hline \multirow[t]{2}{*}{ SLOW 7} & 26.3 & 15.36 & 22.69 & 64.35 & 183.63 \\
\hline & 29.09 & 19.96 & 23.25 & 72.3 & 209.64 \\
\hline Sig. & 0.015 & 0.255 & 0.001 & & 0.763 \\
\hline
\end{tabular}


Figure 10: Between strains comparison of cell layer volumes: Molecular/Purkinje layer (ML), glial cell layer (GL), white matter volume and total cerebellar volume (CB). Significant differences were found in both the ML and white matter layers. 


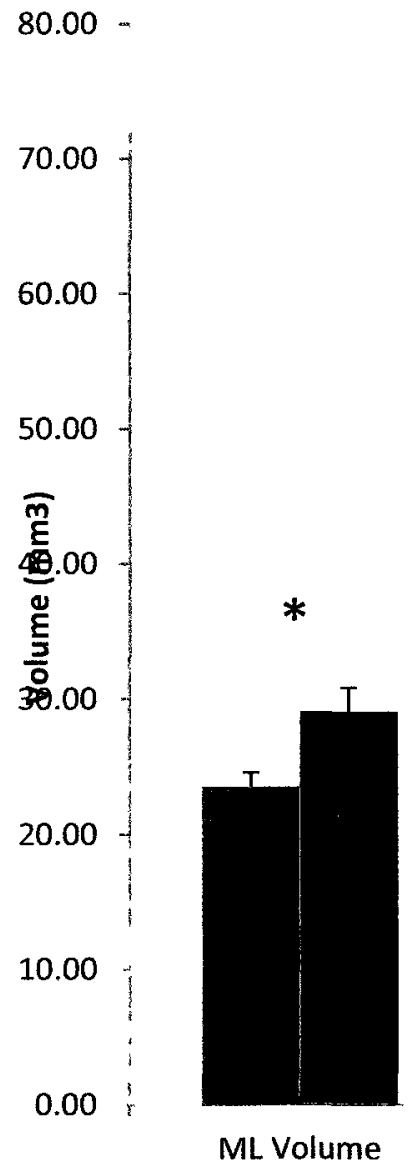

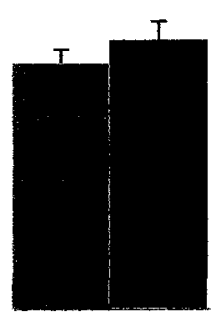

GL Volume

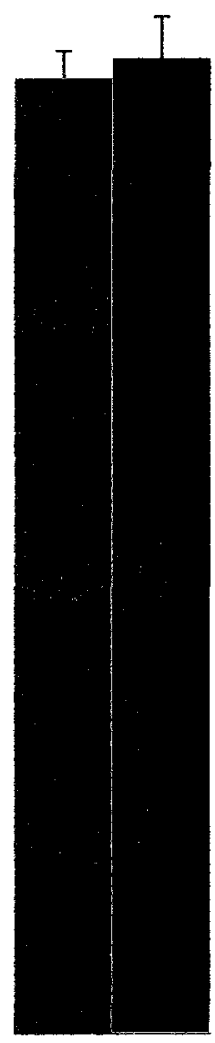

CB Volume
FAST

- SLOW 


\section{Discussion}

The purpose of this thesis was to identify what, if any, anatomical differences exist between a strain of genetically seizure-prone (FAST) and seizure-resistant (SLOW) rats, utilizing a combination of MRI structural analysis and stereological methods. Any differences observed between the two strains could potentially shed light on the ultimate biological causes for their behavioural phenotypes and their relative susceptibility (FAST) or resistance (SLOW) to kindling and the development of TLE. As an adjunct to this, it was hoped that the FAST strain, which shares many behavioural characteristics with the autistic spectrum of disorders seen in humans, would compare favourably on a structural level to what has been shown in human autistic brains. Any similarities between the strain and what has been reported in the human condition could open the door for further research into the cementing of construct validity for the FAST strain as an animal model for ASD. It should be noted in the discussion of these results that the SLOW strain does not represent a 'normal' phenotype, as they were bred to be a counterpoint to the FAST strain. Just as they were bred for seizure susceptibility, the SLOW strain was selectively bred for a resistance to the kindling process. Thus any differences shown between the strains may or may not be indicative of how these rats would compare to their parental strains or any other 'wild-type' strain of rat.

\section{Corpus Callosum}

In order to accomplish these goals, the brain structures explored correspond with those structures that have the strongest body of research connecting them to the development of ASDs. This list includes most often the cerebellum, corpus callosum and the frontal lobe region of the brain (Amaral et al., 2008; Bauman \& Kemper, 2005; 
Hallahan et al., 2009). Previous MRI data, primarily on human subjects, has suggested that autistic patients may have a significantly smaller corpus callosum than control subjects (Freitag et al., 2009; Boger-Megiddo et al., 2006; Vidal et al., 2006), caused primarily by a lower number, with no change in quality, of fibres crossing between the cerebral hemispheres. In addition to this, research into various forms of epilepsy has repeatedly shown that epileptic patients also experience a reduced corpus callosum volume, particularly in the posterior regions (Kim et al., 2008; Hardan et al., 2009). The degree of corpus callosum atrophy has also been correlated to longer duration of epileptic episodes (O'Dwyer et al., 2010). What was found in the current study, however, was exactly the opposite. FAST animals, expected to show a phenotype similar to cases of TLE or ASD, showed instead an average corpus callosum volume approximately $10 \%$ larger than their SLOW counterparts, who typically model a resistance to the development of seizures. In addition to this, the overall shape of the corpus callosum differed between strains, with the FAST animals having a corpus callosum that was generally longer when viewed in the horizontal axis (Figure 8). The overall thickness of the tissue, however, was not significantly different between the groups when measured in the coronal axis, in contradiction with earlier research done by the McIntyre lab (McIntyre \& Gilby, 2005). In that previous study, it was shown that the corpus callosum appeared thinner in the anterior portion of the brains of FAST rats when compared to SLOWs, which the authors hypothesized was due to a decrease of myelin surrounding the fibres or improper wrapping of the myelin sheath. As a possible explanation for the discrepancy between the literature and the results reported here, it should be noted that the animals in this study never once experienced a generalized seizure, the FAST strain simply has a higher susceptibility for developing seizures in a kindling paradigm. The 
importance of this is that there is no clear consensus as to whether corpus callosum atrophy seen in epileptic patients is present before the onset of seizures or whether the tissue atrophy is as a result of the epileptic condition (Weber et al., 2007). It is entirely possible that fully kindled FAST and SLOW animals experiencing stage 5 seizures could show significant atrophy in the corpus callosum compared to the healthy individuals measured in this project.

As for what the larger volume might mean for the development of seizures, there are a number of possibilities. In the simplest scenario, this difference could directly translate to more interhemispheric connections between contralateral structures. With more paths for simple seizures to take between hemispheres, this could have the effect of decreasing the threshold of recruitment for contralateral structures in the brain, leading to generalized seizures. It is also possible that the perceived difference in volume is not due to a difference in the number of axons but instead could represent a change in the way the corpus callosum is organized. As has been previously stated, the FAST animals have been shown to be deficient in key proteins (MBP and PLP) involved in the development and maintenance of the myelin sheath. If the axons in the corpus callosum did not properly develop or are improperly wrapped in myelin, this could manifest itself as a larger but less organized corpus callosum. As discussed earlier, FAST animals show significant developmental delay with respect to proper responses to righting reflex and cliff avoidance, as well as a delay in eye-opening which is a fundamental marker of proper neurodevelopment. If the growth and development of the corpus callosum (or any other brain structure) is similarly delayed or out of synchrony with the rest of the brain, organizational anomalies and deficits are likely to develop. 


\section{Cerebellum}

The cerebellum, a primary focus of this study because of its heavy involvement in the etiology of both TLE and ASD, was divided into anterior, posterior and flocculonodular sections using anatomical markers for defining the boundaries of the structures. Of the three regions of the cerebellum that were traced, two of them (anterior and posterior lobes) were found to be significantly different between the two strains. With regards to the anterior lobe (lobules 1-5), which has functionally been linked to coordination of the lower extremities as well as unconscious proprioception in humans (Gilman et al., 1986; (GillBody, Popat, Parker, \& Krebs, 1997), the FAST strain showed a significant difference in volume compared to the SLOWs, larger by approximately $8 \%$. In contrast, the posterior lobe of the FAST rats was found to be significantly smaller in volume when compared to their SLOW counterparts by an average of $15 \%$. The posterior lobe of the cerebellum (lobules 6-7) has been shown experimentally to be involved with the visual system through a circuit running through the superior colliculus and thalamus, and has been implicated in the ability to shift visual attention, responding to novel stimuli and new environment exploration (Pierce \& Courchesne, 2001; Fransen et al., 1998; Caston et al., 1998). As we could expect then, there is significant experimental evidence to indicate that deficiencies in these cognitive abilities are directly correlated to a reduced volume of cerebellar lobules 6-7 (Carper \& Courchesne, 2000; Caston et al., 1998). It has also been observed that complete ablation of lobule 6 within the posterior lobe can completely abolish classical conditioning (Schreurs, Sanchezandres, \& Alkon, 1991). This could indicate a direct link between the cerebellum and associative learning in the frontal lobe. Overall, dysfunction of these cerebellar lobules could be seen as a possible root cause of the behavioural deficiencies seen in the FAST strain related to various 
learning and attention tasks. In relation to epilepsy, atrophy of the posterior lobes of the cerebellum are common observations, as is a higher volume in the anterior lobe (Crooks, Mitchell, \& Thom, 2000; Oyegbile et al., 2009). Again, like in the corpus callosum, it is unclear whether or not the atrophy of the posterior lobe is a contributing factor for the development of epilepsy or whether epileptic activity is a precursor to the deterioration of cerebellar tissue. The reality is that it is likely a combination of the two, acting on each other in a cycle that leads to the escalation of the disorder if left untreated (Oyegbile et al., 2009). The change in volume of the anterior cerebellum, however, is not what would be expected in the autistic phenotype. Traditionally there has been no significant difference found between ASD subjects and control groups (Hashimoto et al., 1995; Bauman, 1991) in the anterior cerebellum, and as a consequence there has been little recent research into this region. There is only a single study that has been able to report a higher volume in the anterior lobes of the cerebellum in cases of TLE (Oyegbile et al., 2009). While it is impossible to determine from the data gathered in this study what may ultimately be causing this difference in volume, there are several intriguing possibilities that could be explored in future research endeavours. First of all, as seen in the corpus callosum, the reported differences could be due to a higher amount of white matter present in the cerebellum. There are many more white matter fibres that pass through the anterior lobe compared to the posterior and flocculonodular lobes, primarily because many fibers originating in or destined for those lobules must travel through the anterior lobe to reach the deep cerebellar nuclei and the brainstem. Indeed, from the stereological data gathered in this experiment, we can see that the white matter layer of the cerebellum in FAST animals was $25 \%$ larger than that in the SLOW strain. While these data were not analyzed by lobule, only in a global cerebellar sense, it is reasonable to hypothesize that 
the anterior lobe could easily be the source of the bulk of the measured difference, based on the reasons indicated above.

\section{Stereology}

Perhaps the most interesting finding of this project was that there was a significant difference (14\% fewer) in the number of Purkinje cells in the cerebellum of the FAST strain compared to the SLOW strain. These GABAergic cells are the primary source of neurochemical signalling in the cerebellum, receiving the majority of afferent signals and coordinating activity for the vast majority of cerebellar output channels (Whitney, Kemper, Rosene, Bauman, \& Blatt, 2009).

The loss of Purkinje neurons we see in the cerebellum is perhaps most relevant if discussed from the perspective of the GABA hypothesis of epilepsy. The hypothesis postulates that a lower number of GABAergic inhibition of neural circuits can directly lead to epileptic activity in the brain through unregulated, spontaneous neuronal firing, while an abundance of inhibitory circuitry can act as a neuroprotectant (Dedeyn, Marescau, \& Macdonald, 1990). Purkinje cell loss has also been a hallmark symptom of epilepsy (Hermann, Bayless, Hansen, Parrish, \& Seidenberg, 2005) If, as has been demonstrated here, there are a significantly lower number of Purkinje cells inherent to the FAST strain, it is possible that a great many circuits could be affected throughout the brain. The natural stop order that is sent out from Purkinje cells to inhibit neural activity could be diminished to the point where unchecked spontaneous neuron firing may become a problem in those regions to which the Purkinje cells send their information. Over time this hyperactivity could reduce the threshold that must be overcome to develop a generalized seizure. 
Table 7: Results summary of the current study, with comparison to literature from the established epilepsy and autistic spectrum of disorders (ASD). Only significant differences are reported below

Results Summary

MRI

\begin{tabular}{cllc}
\hline Structure & Epilepsy & ASD & Strain Comparison \\
\hline Cerebellum & < Control & No Diff. & No Diff. \\
Anterior & No Diff. & No Diff. & FAST $>$ SLOW \\
Posterior & $<$ Control & < Control & FAST < SLOW \\
Flocculonodular & No Diff. & No Diff. & No Diff. \\
Corpus Callosum & $<$ Control & $<$ Control & FAST $>$ SLOW \\
Frontal Lobes & $<$ Control & No Diff. & No Diff. \\
\hline
\end{tabular}

Stereology

\begin{tabular}{cccc}
\hline Purkinje cell \# & $<$ Control & $<$ Control & FAST $<$ SLOW \\
Cell Layers & & & \\
Molecular & $<$ Control & $<$ Control & FAST $<$ SLOW \\
Granule & Inconclusive & Inconclusive & No Diff. \\
White Matter & $<$ Control & $<$ Control & FAST $>$ SLOW
\end{tabular}


Purkinje cells project primarily to the four deep cerebellar nuclei within the white matter of the cerebellum (Apps \& Hawkes, 2009; Limperopoulos \& du Plessis, 2006): the dentate, emboliform, globose and fastigial nuclei. The most important of these with respect to learning and coordination (of chief concern when examining the FAST strain's behavioural characteristics), are the dentate and emboliform nuclei. The dentate nucleus projects primarily through the thalamus to both the primary motor cortex and the parietal cortex, and is involved in learning new motor tasks and solving logic problems that require motor skill (Voogd, 2003). The emboliform nucleus also passes through the thalamus via the red nuclei and projects directly to the primary motor cortex. This circuit has been implicated in the maintenance of balance and the coordination of involuntary movements (Voogd, 2003; Apps \& Hawkes, 2009). Reduced inhibition of these circuits by Purkinje cell degeneration could severely damage their ability to inhibit activity in the cerebrum and cause many of the motor problems that are associated with ASD, including involuntary or repetitive motions, inability to maintain attention and confusion about one's surroundings. A significant reduction in the inhibition on the motor cortex could explain the strain's propensity for stereotyped, repetitive movements.

As mentioned previously, the volume of the cell layers in the cerebellum were measured to determine if there was a significant difference in the overall size of the Purkinje/molecular cell layer, granule cell layer and white matter layer. There was a significant $25 \%$ difference in the total volume of the white matter layer, with the FAST strain having more when compared to the SLOWs, as well as $19 \%$ change in the volume of the molecular layer of FAST vs. SLOW rats. There was no significant difference found in the granule cell layer. 
The change in molecular layer volume seen in the FAST phenotype corroborates well with the $14 \%$ change in the number of Purkinje cells, but raises the question of whether other cells in the layer may be affected as well. It has been well established that the damage seen in Purkinje cell populations in epileptic brains extends to the supporting cells: stellate and basket neurons (Pitkanen \& Lukasiuk, 2009) as well. It is possible that a change in the number of supporting cells could be contributing to the observed volume difference between FAST and SLOW strains. This possibility is tempered somewhat, however, by the fact that the rats involved in this study did not experience any epileptic activity during their lives, so any damage to neural circuitry would have to be inherent in the strain and not due to seizure-induced atrophy. There is no literature available exploring the state of these supporting cells in naive, seizure susceptible animals. With respect to the autistic spectrum of disorders, prior research does not indicate any significant change in either supporting cell type (Whitney et al., 2009; Schumann \& Nordahl, 2011), but there is evidence that these cells up-regulate their activity in order to compensate for the loss of Purkinje cell function (Yip, Soghomonian, \& Blatt, 2007) seen in many individuals. This change to GABAergic input to the Purkinje cell population might act to modulate cerebellar output to the deep cerebellar nuclei.

\section{Frontal Lobes}

Tracing of the frontal lobes revealed no significant difference in region volume between the strains, indicating that the FAST strain does not seem to exhibit the 5-10\% higher frontal lobe volume that has been reported in ASD children (Amaral et al., 2008; Freitag et al., 2009). This may be due to the use of adult rat brains in these experiments, as the difference in frontal lobe volume seen in humans tends to diminish or disappear 
altogether at the onset of adolescence (Piven, Arndt, Bailey, \& Andreasen, 1996;

Mosconi, Zwaigenbaum, \& Piven, 2006). There also did not appear to be any significant correlation between frontal lobe volume and posterior cerebellum volume; one of the more consistent findings in human ASD research (Carper \& Courchesne, 2000;

Ciesielski, Harris, Hart, \& Pabst, 1997). This again may be because the animals in the current study were not of the ideal age to show this difference.

\section{The FAST phenotype: Ultimate Causes}

At present time there is a great deal of research being done to try and shed light on why exactly Purkinje cell populations are so specifically affected by autistic spectrum disorders and/or epilepsy. In the latter case, while there is a great deal of debate as to whether or not Purkinje cell loss occurs in advance of the development of seizures, there is little debate over the fact that once epilepsy is fully developed, the physiological stress caused by the disorder continues to ravage cell populations (Hermann et al., 2005). ASDs, on the other hand, do not for the most part have such an obvious and chronic stressor. Whatever difference exists in the Purkinje cell population is due to differences in early stages of neurodevelopment (Amaral et al., 2008), either from dysfunction of cellular differentiation, neural migration or circuit formation. These changes are most likely in place before or very shortly after birth. While secondary damage may occur, it is likely this initial breakdown of normal neural development that leads to a state in which further damage can occur.

With respect to the FAST strain, there remains no concrete answer to the question of what ultimately causes the behavioural and neurological phenotype that has been so consistently observed these past decades, but recently a new avenue of research has 
opened up that offers great promise. It has been observed that when compared to the SLOW strain, the FAST animals have much lower levels of free fatty acids (FFAs) in their bloodstream (St-Onge, McIntyre, \& Gilby, 2008; Gilby et al., 2009). The importance of this is that FFAs have been shown to be incredibly important in early neurodevelopment and the creation and maintenance of the myelin sheath. A decrease in FFA levels has also been conclusively linked to both epilepsy and ASDs (Yuen et al., 2005; Richardson \& Puri, 2000). Conversely, the introduction of a high fat diet, which has the effect of increasing FFA concentrations, has been shown to have a profound effect in reducing the frequency and severity of seizures in epileptic patients (Freeman, 2009). While the exact nature of the fatty acid deficiency in the FAST strain is still under investigation, the fact that this relationship exists aids us in directing attention to areas of the brain that would show the most dysfunction if myelination were impaired in some way. The significant difference in the size of the white matter layer of the cerebellum and the corpus callosum, as well as differences in the shape of the corpus callosum between strains seem to fit neatly into the picture being drawn by the behavioural and molecular data related to lipid handling, as a dysfunction of myelin related proteins (such as MBP and PLP), as previously discussed, can lead to changes in the way circuits are organized and the size of their myelin sheaths. Loosely packed myelin bundles could potentially help explain the higher white matter volume in the cerebellum observed despite the loss of Purkinje Cells.

\section{Future Directions}

While this study found a number of interesting differences between the FAST and SLOW strains, there remain a great number of questions left to be answered. The 
differences between the volumes of the cerebellar lobules and the cellular layers need to be further refined. The interaction between smaller numbers of Purkinje cells and the higher white matter volume may be confounding the magnitude of these results. Future research may seek to use stereology to separate the white matter data by lobule in order to get a better picture of where exactly the differences are more prominent. This in turn might explain why the anterior cerebellum is larger in FAST animals compared to SLOWs, while the posterior cerebellum is smaller. Stereological counts of other cell populations, such as the granule cells and stellate/basket cells could also add further clarity to the picture we have of strain differences in the cerebellum.

While this study focused primarily on those structures that have been most closely tied to both epilepsy and autistic spectrum disorders, further work should be done to examine other structures that have been associated with one or both of these conditions. The anterior commissure could act as a very interesting point of comparison for the corpus callosum data shown here. Similarly, structures that have been at the core of studying the FAST and SLOW strains, the amygdala and hippocampus, should be investigated in depth to determine what strain differences exist. Unfortunately the MRI scans taken for this study did not have a high enough colour contrast to easily pick them (amygdala and hippocampus) out from surrounding tissue. Study into these two structures would aid immensely in developing an understanding of the neural circuitry in the temporal lobes that is altered in both strains.

In the future it may also be prudent to attempt replication of these data with behavioural data for the same animals involved. It has long been suspected that the degree of deviation from the SLOW and parental strains could be directly correlated with brain pathology and if a sense of predictive validity could be attached to the strain, it 
would add a lot of weight to its inclusion as an animal model for autistic spectrum disorders.

\section{Conclusions}

In summary, this project has uncovered a number of novel strain differences between the FAST and the SLOW rats. The corpus callosum of the FAST rat is $10 \%$ larger than in their SLOW cousins, possibly caused by abnormalities in myelin development. The posterior lobe of the cerebellum in the FAST strain was shown to be significantly smaller than their SLOW counterparts, potentially caused by the smaller number of Purkinje cells. In the animals measured for this project, that difference in the Purkinje cells was $14 \%$ of the total cell population. Despite this, however, the anterior lobe of the cerebellum was found to be significantly larger in the FAST strain compared to SLOWs. Combined with the finding that the FAST strain possessed $25 \%$ more cerebellar white matter than the SLOWs, it is reasonable to postulate that since the anterior lobe contains most of the white matter fibres in the cerebellum that the higher white matter volume may be masking a difference in the volume of the Purkinje cell layer (Results summarized in Table 7).

Ultimately, the results reported here represent a number of novel strain differences between FAST and SLOW animals. While the cerebellum data, both from MRI and stereology map well to human epilepsy and ASD, the contradiction between the established literature and the reported results with respect to differences in white matter between the strains throws a proverbial wrench in the idea that the FAST strain may represent a model for the autistic spectrum of disorders. Future research will face the task of untangling the ultimate causes of these findings before any further conclusions can be 
drawn. The FAST strain has a long road ahead of it to establish itself as a credible model of ASD-like characteristics. 


\section{References}

Abrahams, B. S. \& Geschwind, D. H. (2010). Connecting Genes to Brain in the Autism Spectrum Disorders. Archives of Neurology, 67, 395-399.

Amaral, D. G., Schumann, C. M., \& Nordahl, C. W. (2008). Neuroanatomy of autism. Trends Neurosci., 31, 137-145.

American Psychological Association (2000). Diagnostic and statistical manual of mental disorders: fourth edition text revision. (4 ed.) Washington, D.C..

Anisman, H. \& McIntyre, D. C. (2002). Conceptual, spatial, and cue learning in the Morris water maze in fast or slow kindling rats: attention deficit comorbidity. J.Neurosci., 22, 7809-7817.

Apps, R. \& Hawkes, R. (2009). Cerebellar cortical organization: a one-map hypothesis. Nature Reviews Neuroscience, 10, 670-681.

Banerjee, P. N., Filippi, D., \& Hauser, W. A. (2009). The descriptive epidemiology of epilepsy-A review. Epilepsy Research, 85, 31-45.

Bauman, M. L. (1991). Microscopic Neuroanatomical Abnormalities in Autism. Pediatrics, 87, 791-796.

Bauman, M. L. \& Kemper, T. L. (2005). Neuroanatomic observations of the brain in autism: a review and future directions. Int.J.Dev.Neurosci., 23, 183-187.

Belzung, C., Leman, S., Vourc'h, P., \& Andres, C. (2005). Rodent models for autism: A critical review. Drug Discovery Today, 2, 93-101. 
Boger-Megiddo, I., Shaw, D. W., Friedman, S. D., Sparks, B. F., Artru, A. A., Giedd, J. N. et al. (2006). Corpus callosum morphometrics in young children with autism spectrum disorder. $J$ Autism Dev.Disord, 36, 733-739.

Bolton, P., Macdonald, H., Pickles, A., Rios, P., Goode, S., Crowson, M. et al. (1994). A Case - Control Family History Study of Autism. Journal of Child Psychology and Psychiatry and Allied Disciplines, 35, 877-900.

Bourgeron, T., Jamain, S. p., \& Granon, S. (2006). Animal Models of Autism. In G.S.Fisch \& J. Flint (Eds.), Transgenic and Knockout Models of Neuropsychiatric Disorders (pp. 151-174). Humana Press.

Canitano, R. (2007). Epilepsy in autism spectrum disorders. European Child \& Adolescent Psychiatry, 16, 61-66.

Carper, R. A. \& Courchesne, E. (2000). Inverse correlation between frontal lobe and cerebellum sizes in children with autism. Brain, 123 (Pt 4), 836-844.

Caston, J., Yon, E., Mellier, D., Godfrey, H. P., Delhaye-Bouchaud, N., \& Mariani, J. (1998). An animal model of autism: behavioural studies in the GS guinea-pig. European Journal of Neuroscience, 10, 2677-2684.

Ciesielski, K. T., Harris, R. J., Hart, B. L., \& Pabst, H. F. (1997). Cerebellar hypoplasia and frontal lobe cognitive deficits in disorders of early childhood. Neuropsychologia, 35, 643-655. 
Cockerell, O. C., Sander, J. W., \& Shorvon, S. D. (1995). Remission of epilepsy. The NGPS. National General Practice Study of Epilepsy. Lancet, 346, 1228.

Colter, A. L., Cutler, C., \& Meckling, K. A. (2008). Fatty acid status and behavioural symptoms of attention deficit hyperactivity disorder in adolescents: a case-control study. Nutr.J, 7, 8.

Courchesne, E., Karns, C. M., Davis, H. R., Ziccardi, R., Carper, R. A., Tigue, Z. D. et al. (2001). Unusual brain growth patterns in early life in patients with autistic disorder - An MRI study. Neurology, 57, 245-254.

Crooks, R., Mitchell, T., \& Thom, M. (2000). Patterns of cerebellar atrophy in patients with chronic epilepsy: a quantitative neuropathological study. Epilepsy Research, $41,63-73$

Danielsson, S., Gillberg, I. C., Billstedt, E., Gillberg, C., \& Olsson, I. (2005). Epilepsy in young adults with autism: A prospective population-based follow-up study of 120 individuals diagnosed in childhood. Epilepsia, 46, 918-923.

Dedeyn, P. P., Marescau, B., \& Macdonald, R. L. (1990). Epilepsy and the GabaHypothesis - A Brief Review and Some Examples. Acta Neurologica Belgica, 90, $65-81$

Deth, R., Muratore, C., Benzecry, J., Power-Charnitsky, V. A., \& Waly, M. (2008). How environmental and genetic factors combine to cause autism: A redox/methylation hypothesis. Neurotoxicology, 29, 190-201. 
DiCicco-Bloom, E., Lord, C., Zwaigenbaum, L., Courchesne, E., Dager, S. R., Schmitz, C. et al. (2006). The developmental neurobiology of autism spectrum disorder. J.Neurosci., 26, 6897-6906.

Ecker, C., Marquand, A., Mourao-Miranda, J., Johnston, P., Daly, E. M., Brammer, M. J. et al. (2010). Describing the brain in autism in five dimensions--magnetic resonance imaging-assisted diagnosis of autism spectrum disorder using a multiparameter classification approach. $J$ Neurosci., 30, 10612-10623.

Edwards, A. M., Ross, N. W., Ulmer, J. B., \& Braun, P. E. (1989). Interaction of Myelin Basic-Protein and Proteolipid Protein. Journal of Neuroscience Research, 22, 97102.

Engel, J. (2006). ILAE classification of epilepsy syndromes. Epilepsy Research, 70, S5S10.

Fombonne, E. (2002). Epidemiological trends in rates of autism. Mol.Psychiatry, 7 Suppl 2, S4-S6.

Fombonne, E. (2003). The prevalence of autism. JAMA, 289, 87-89.

Fransen, E., D'Hooge, R., Van Camp, G., Verhoye, M., Sijbers, J., Reyniers, E. et al. (1998). L1 knockout mice show dilated ventricles, vermis hypoplasia and impaired exploration patterns. Human Molecular Genetics, 7, 999-1009.

Freeman, J. M. (2009). The Ketogenic Diet: Additional Information From a Crossover Study. Journal of Child Neurology, 24, 509-512. 
Freitag, C. M., Agelopoulos, K., Huy, E., Rothermundt, M., Krakowitzky, P., Meyer, J. et al. (2010). Adenosine $A(2 A)$ receptor gene (ADORA2A) variants may increase autistic symptoms and anxiety in autism spectrum disorder. Eur.Child Adolesc.Psychiatry, 19, 67-74.

Freitag, C. M., Luders, E., Hulst, H. E., Narr, K. L., Thompson, P. M., Toga, A. W. et al. (2009). Total brain volume and corpus callosum size in medication-naive adolescents and young adults with autism spectrum disorder. Biol.Psychiatry, 66, 316-319.

Gaspar, P., Cases, O., \& Maroteaux, L. (2003). The developmental role of serotonin: news from mouse molecular genetics. Nat.Rev.Neurosci., 4, 1002-1012.

Gernsbacher, M. A., Dawson, M., \& Goldsmith, H. H. (2005). Three reasons not to believe in an autism epidemic. Current Directions in Psychological Science, 14, $55-58$.

Geschwind, D. H. (2008). Autism: Many Genes, Common Pathways? Cell, 135, 391-395.

Gilby, K. L. (2008). A new rat model for vulnerability to epilepsy and autism spectrum disorders. Epilepsia, 49, 108-110.

Gilby, K. L., Jans, J., \& McIntyre, D. C. (2009). Chronic Omega-3 Supplementation in Seizure-Prone Versus Seizure-Resistant Rat Strains: A Cautionary Tale. Neuroscience, 163, 750-758. 
Gilby, K. L., Thorne, V., Patey, A., \& McIntyre (2007). Ruling out post-natal origins to attention-deficit/hyperactivity (ADHD)-like behaviours in a seizure-prone rat strain. Behavioral Neurosi, 121, 370-379.

GillBody, K. M., Popat, R. A., Parker, S. W., \& Krebs, D. E. (1997). Rehabilitation of balance in two patients with cerebellar dysfunction. Physical Therapy, 77, 534552.

Hagemann, G., Lemieux, L., Free, S. L., Krakow, K., Everitt, A. D., Kendall, B. E. et al. (2002). Cerebellar volumes in newly diagnosed and chronic epilepsy. $J$ Neurol., 249, $1651-1658$.

Hallahan, B., Daly, E. M., McAlonan, G., Loth, E., Toal, F., O'Brien, F. et al. (2009). Brain morphometry volume in autistic spectrum disorder: a magnetic resonance imaging study of adults. Psychological Medicine, 39, 337-346.

Hara, H. (2007). Autism and epilepsy: A retrospective follow-up study. Brain \& Development, 29, 486-490.

Hardan, A. Y., Pabalan, M., Gupta, N., Bansal, R., Melhem, N. M., Fedorov, S. et al. (2009). Corpus callosum volume in children with autism. Psychiatry ResearchNeuroimaging, 174, 57-61.

Hashimoto, T., Tayama, M., Murakawa, K., Yoshimoto, T., Miyazaki, M., Harada, M. et al. (1995). Development of the Brain-Stem and Cerebellum in Autistic Patients. Journal of Autism and Developmental Disorders, 25, 1-18. 
Hazlett, H. C., Poe, M., Gerig, G., Smith, R. G., Provenzale, J., Ross, A. et al. (2005). Magnetic resonance imaging and head circumference study of brain size in autism: birth through age 2 years. Arch.Gen.Psychiatry, 62, 1366-1376.

Hermann, B. P., Bayless, K., Hansen, R., Parrish, J., \& Seidenberg, M. (2005). Cerebellar atrophy in temporal lobe epilepsy. Epilepsy \& Behavior, 7, 279-287.

Hertz-Picciotto, I. (2008). Introduction to Environmental influence on Psychiatric Disorders in Children and Adolescents. Epidemiology, 19, S40.

Jeffreys, J. G. R. (1999). Hippocampal sclerosis and temporal lobe epilepsy: cause or consequence? Brain, 122, 1007-1008.

Ke, X., Tang, T., Hong, S., Hang, Y., Zou, B., Li, H. et al. (2009). White matter impairments in autism, evidence from voxel-based morphometry and diffusion tensor imaging. Brain Res., 1265, 171-177.

Kim, H., Piao, Z., Liu, P., Bingaman, W., \& Diehl, B. (2008). Secondary white matter degeneration of the corpus callosum in patients with intractable temporal lobe epilepsy: a diffusion tensor imaging study. Epilepsy Res., 81, 136-142.

King, J. T. \& Lamotte, C. C. (1989). El Mouse As A Model of Focal Epilepsy - A Review. Epilepsia, 30, 257-265.

Klauck, S. M. \& Poustka, A. (2006). Animal models of autism. Drug Discovery Today: Disease Models, 3, 313-318. 
Klugmann, M., Schwab, M. H., Puhlhofer, A., Schneider, A., Zimmermann, F., Griffiths, I. R. et al. (1997). Assembly of CNS myelin in the absence of proteolipid protein. Neuron, 18, 59-70.

Kogan, M. D., Strickland, B. B., Blumberg, S. J., Singh, G. K., Perrin, J. M., \& van Dyck, P. C. (2008). A National Profile of the Health Care Experiences and Family Impact of Autism Spectrum Disorder Among Children in the United States, 20052006. Pediatrics, 122, E1149-E1158.

Lancaster, K., Dietz, D. M., Moran, T. H., \& Pletnikov, M. V. (2007). Abnormal social behaviors in young and adult rats neonatally infected with Borna disease virus. Behav.Brain Res., 176, 141-148.

Larsen, J. O., Skalicky, M., \& Viidik, A. (2000). Does long-term physical exercise counteract age-related Purkinje cell loss? A stereological study of rat cerebellum. Journal of Comparative Neurology, 428, 213-222.

Leonard, H., Dixon, G., Whitehouse, A. J. O., Bourke, J., Aiberti, K., Nassar, N. et al. (2010). Unpacking the complex nature of the autism epidemic. Research in Autism Spectrum Disorders, 4, 548-554.

Levisohn, P. M. (2007). The autism-epilepsy connection. Epilepsia, 48 Suppl 9, 33-35.

Limperopoulos, C. \& du Plessis, A. J. (2006). Disorders of cerebellar growth and development. Current Opinion in Pediatrics, 18, 621-627. 
Marin, J. C., Moura, P. J., Cysneiros, R. M., Colugnati, D. B., Cavalheiro, E. A., Scorza, F. A. et al. (2008). Temporal lobe epilepsy and social behavior: an animal model for autism? Epilepsy Behav., 13, 43-46.

McIntyre, D. C. \& Gilby, K. L. (2005). Electrophysiological and anatomical differences, behavioral comorbidities and gene expression in Fast and Slow kindling rat strains. In (M.E. Corcoran \& S.L. Moshe Eds ed..

McIntyre, D. C. \& Gilby, K. L. (2008). Mapping seizure pathways in the temporal lobe. Epilepsia, 49, 23-30.

McIntyre, D. C., Kent, P., Hayley, S., Merali, Z., \& Anisman, H. (1999). Influence of psychogenic and neurogenic stressors on neuroendocrine and central monoamine activity in fast and slow kindling rats. Brain Res., 840, 65-74.

McIntyre, D. C., Poulter, M. O., \& Gilby, K. (2002). Kindling: some old and some new. Epilepsy Res., 50, 79-92.

Meidenbauer, J. J., Mantis, J. G., \& Seyfried, T. N. (2011). The EL mouse: A natural model of autism and epilepsy. Epilepsia, 52, 347-357.

Mosconi, M., Zwaigenbaum, L., \& Piven, J. (2006). Structural MRI in autism: Findings and future directions. Clinical Neuroscience Research, 6, 135-144.

O'Dwyer, R., Wehner, T., LaPresto, E., Ping, L., Tkach, J., Noachtar, S. et al. (2010). Differences in corpus callosum volume and diffusivity between temporal and frontal lobe epilepsy. Epilepsy \& Behavior, 19, 376-382. 
Obrien, J. S. \& Sampson, E. L. (1965). Lipid Composition of Normal Human Brain Gray Matter White Matter and Myelin. Journal of Lipid Research, 6, 537-\&.

Oyegbile, T., Dabbs, K., Jones, J., Rutecki, P., Pierson, R., Seidenberg, M. et al. (2009). The Nature and Extent of Cerebellar Atrophy in Chronic Temporal Lobe Epilepsy. Epilepsia, 50, 67-68.

Pierce, K. \& Courchesne, E. (2001). Evidence for a cerebellar role in reduced exploration and stereotyped behavior in autism. Biological Psychiatry, 49, 655-664.

Pitkanen, A. \& Lukasiuk, K. (2009). Molecular and cellular basis of epileptogenesis in symptomatic epilepsy. Epilepsy \& Behavior, 14, 16-25.

Piven, J., Arndt, S., Bailey, J., \& Andreasen, N. (1996). Regional brain enlargement in autism: A magnetic resonance imaging study. Journal of the American Academy of Child and Adolescent Psychiatry, 35, 530-536.

Polanczyk, G., de Lima, M. S., Horta, B. L., Biederman, J., \& Rohde, L. A. (2007). The worldwide prevalence of ADHD: a systematic review and metaregression analysis. Am.J.Psychiatry, 164, 942-948.

Rabinovitz, S., Mostofsky, D. I., \& Yehuda, S. (2004). Anticonvulsant efficiency, behavioral performance and cortisol levels: a comparison of carbamazepine (CBZ) and a fatty acid compound (SR-3). Psychoneuroendocrinology, 29, 113124. 
Racine, R. J., Steingart, M., \& McIntyre, D. C. (1999). Development of kindling-prone and kindling-resistant rats: selective breeding and electrophysiological studies. Epilepsy Res., 35, 183-195.

Reinhart, C. J., Pellis, S. M., \& McIntyre, D. C. (2004). Development of play fighting in kindling-prone (FAST) and kindling-resistant (SLOW) rats: How does the retention of phenotypic juvenility affect the complexity of play? Developmental Psychobiology, 45, 83-92.

Richardson, A. J. \& Puri, B. K. (2000). The potential role of fatty acids in attentiondeficit/hyperactivity disorder. Prostaglandins Leukot.Essent.Fatty Acids, 63, 7987.

Richardson, A. J. \& Puri, B. K. (2002). A randomized double-blind, placebo-controlled study of the effects of supplementation with highly unsaturated fatty acids on ADHD-related symptoms in children with specific learning difficulties. Prog Neuropsychopharmacol Biol Psychiatry 26, 233-239.

Ref Type: Abstract

Rutter, M. (2005). Incidence of autism spectrum disorders: Changes over time and their meaning. Acta Paediatrica, 94, 2-15.

Sagvolden, T., Russell, V. A., Aase, H., Johansen, E. B., \& Farshbaf, M. (2005). Rodent models of attention-deficit/hyperactivity disorder. Biol.Psychiatry, 57, 1239-1247.

Schlanger, S., Shinitzky, M., \& Yam, D. (2002). Diet enriched with omega-3 fatty acids alleviates convulsion symptoms in epilepsy patients. Epilepsia, 43, 103-104. 
Schmitz, C., Born, M., Dolezel, P., Rutten, B. P. F., De Saint-Georges, L., Hof, P. R. et al. (2005). Prenatal protracted irradiation at very low dose rate induces severe neuronal loss in rat hippocampus and cerebellum. Neuroscience, 130, 935-948.

Schreurs, B. G., Sanchezandres, J. V., \& Alkon, D. L. (1991). Learning-Specific Differences in Purkinje-Cell Dendrites of Lobule Hvi (Lobulus Simplex) Intracellular-Recording in A Rabbit Cerebellar Slice. Brain Research, 548, 18-22.

Schumann, C. M., Hamstra, J., Goodlin-Jones, B. L., Lotspeich, L. J., Kwon, H., Buonocore, M. H. et al. (2004). The amygdala is enlarged in children but not adolescents with autism; The hippocampus is enlarged at all ages. Journal of Neuroscience, 24, 6392-6401.

Schumann, C. M. \& Nordahl, C. W. (2011). Bridging the gap between MRI and postmortem research in autism. Brain Research, 1380, 175-186.

Scott, J. A., Schumann, C. M., Goodlin-Jones, B. L., \& Amaral, D. G. (2009). A comprehensive volumetric analysis of the cerebellum in children and adolescents with autism spectrum disorder. Autism Res., 2, 246-257.

Shattuck, P. T. (2006). The contribution of diagnostic substitution to the growing administrative prevalence of autism in US special education. Pediatrics, 117 , 1028-1037.

St-Onge, V., McIntyre, D. C., \& Gilby, K. L. (2008). Use of A Seizure-Prone Strain of Animals in the Study of Ad/Hd and Asd-Like Behaviours Comorbid with Epilepsy. Epilepsia, 49, 274-275. 
Stanfield, A. C., McIntosh, A. M., Spencer, M. D., Philip, R., Gaur, S., \& Lawrie, S. M. (2008). Towards a neuroanatomy of autism: a systematic review and metaanalysis of structural magnetic resonance imaging studies. Eur.Psychiatry, 23, 289-299.

Tuchman, R. \& Rapin, I. (2002). Epilepsy in autism. Lancet Neurology, 1, 352-358.

Verhoeven, J. S., De, C. P., Lagae, L., \& Sunaert, S. (2010). Neuroimaging of autism. Neuroradiology, 52, 3-14.

Vidal, C. N., Nicolson, R., DeVito, T. J., Hayashi, K. M., Geaga, J. A., Drost, D. J. et al. (2006). Mapping corpus callosum deficits in autism: an index of aberrant cortical connectivity. Biol.Psychiatry, 60, 218-225.

Voogd, J. (2003). The human cerebellum. Journal of Chemical Neuroanatomy, 26, 243252.

Wassink, T. H., Piven, J., \& Patil, S. R. (2001). Chromosomal abnormalities in a clinic sample of individuals with autistic disorder. Psychiatric Genetics, 11, 57-63.

Webb, S. J., Sparks, B. F., Friedman, S. D., Shaw, D. W., Giedd, J., Dawson, G. et al. (2009). Cerebellar vermal volumes and behavioral correlates in children with autism spectrum disorder. Psychiatry Res., 172, 61-67.

Weber, B., Luders, E., Faber, J., Richter, S., Quesada, C. M., Urbach, H. et al. (2007). Distinct regional atrophy in the corpus callosum of patients with temporal lobe epilepsy. Brain, 130, 3149-3154. 
Whitney, E. R., Kemper, T. L., Rosene, D. L., Bauman, M. L., \& Blatt, G. J. (2009). Density of Cerebellar Basket and Stellate Cells in Autism: Evidence for a Late Developmental Loss of Purkinje Cells. Journal of Neuroscience Research, 87, $2245-2254$.

Yip, J., Soghomonian, J. J., \& Blatt, G. J. (2007). Decreased GAD67 mRNA levels in cerebellar purkinje cells in autism: pathophysiological implications. Acta Neuropathologica, 113, 559-568.

Young, G. \& Conquer, J. (2005). Omega-3 fatty acids and neuropsychiatric disorders. Reprod.Nutr.Dev., 45, 1-28.

Young, G. S., Maharaj, N. J., \& Conquer, J. A. (2004). Blood phospholipid fatty acid analysis of adults with and without attention deficit/hyperactivity disorder. Lipids, $39,117-123$.

Yuen, A. W., Sander, J. W., Fluegel, D., Patsalos, P. N., Bell, G. S., Johnson, T. et al. (2005). Omega-3 fatty acid supplementation in patients with chronic epilepsy: a randomized trial. Epilepsy Behav., 7, 253-258. 